\title{
PRESERVING A FAMILY'S PHOTOGRAPHIC HISTORY: THE PRIVATE COLLECTION OF MICHINA POPE
}

\author{
By \\ Margalit E. Slovin \\ BFA Ryerson University, 2013 \\ A thesis \\ presented to Ryerson University \\ in partial fulfillment of the \\ requirements for the degree \\ of \\ Master of Arts \\ In the Program of
}

Film and Photograph Preservation and Collections Management

Toronto, Ontario, Canada, 2016.

(C) Margalit E. Slovin, 2016 
I hereby declare that I am the sole author of this thesis. This is a true copy of the thesis, including any required final revisions, as accepted by my examiners.

I authorize Ryerson University to lend this thesis to other institutions or individuals for the purpose of scholarly research.

I further authorize Ryerson University to reproduce this thesis by photocopying or by other means, in total or in part, at the request of other institutions or individuals for the purpose of scholarly research.

I understand that my thesis may be made electronically available to the public. 


\begin{abstract}
Preserving a Family's Photographic History: the Private Collection of Michina Pope Master of Arts 2016

Margalit Slovin

Film and Photography Preservation and Collections Management Ryerson University
\end{abstract}

Photographs can provide a pictorial testimony of a familial history; yet, each time objects are moved and handled the risk of loss and deterioration increases. However, to date, little guidance has been available to private collectors on how to organize and preserve their photographic collections. My practical thesis focuses on the unique challenges of organizing, preserving and digitizing a private collection of approximately 250 glass plate negatives and four corresponding albums, belonging to Michina Pope in Toronto, Canada. Using this specific collection, I have summarized my research with the intention of creating an illustrated manual with clear guidelines as a resource to help guide private collectors in caring for their photographic collection. In lieu of a specifically purposed manual, this thesis paper can act, in the time being, as a guide for collectors and/or those working with private collections of photographic materials. 


\section{ACKNOWLEDGEMENTS}

I would first like to thank the Director of the Film and Photographic Preservation and Collections Management Program, my supervisor, and mentor, Marta Braun, who helped initiate this thesis by recommending my professional services to Michina Pope, the owner of the collection.

Other faculty members who I wish to thank are my two readers: Vid Ingelevics and Denise (Dee) Psaila. As my first reader, Vid provided me with ongoing motivation and an incredible second pair of eyes. Dee, my second reader, was an extremely supportive resource, answering all forms of my communication for almost two years now.

The Ryerson Image Centre team, including Laura Ramsey, Charlene Heath, Jennifer Park, Anna Jedrzejowski, and Chantal Wilson, deserves recognition for their guidance and expertise throughout my residency.

Furthermore, I would still be staring at my computer screen had it not been for the incredible technical support of David Kalman.

I am extremely appreciative of my friends and family for their unwavering support throughout my graduate studies, especially those who have memorized the title of my degree, even though they may not understand what it entails.

Last but not least, this thesis would not have been possible without Michina Pope. I am indebted to her for her incredible patience and willingness to learn alongside me throughout the course of the project. 


\section{TALE OF CONTENTS}

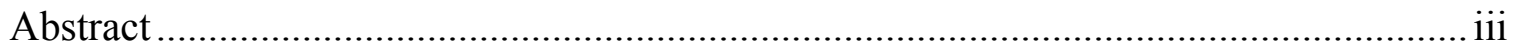

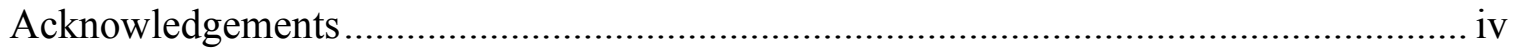

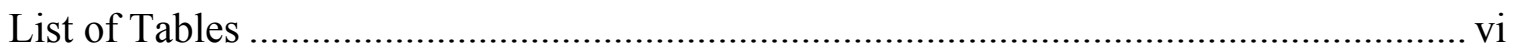

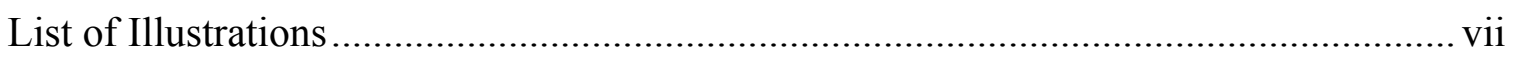

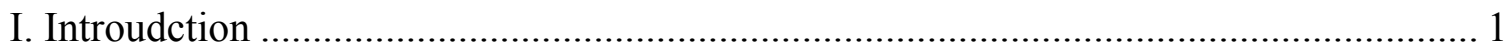

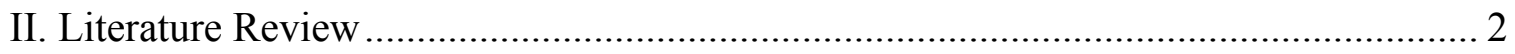

a. Deterioration and Preservation of Glass Plate Negatives ........................................ 2

b. Deterioration and Preservation of Photographic Albums .......................................... 4

c. Digitization of Glass Plate Negatives and Photographic Albums ............................ 5

d. Cataloguing Methods for an Archival Collection.................................................... 7

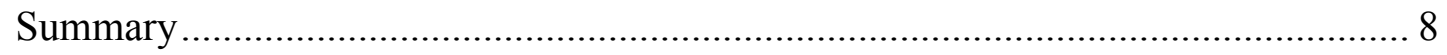

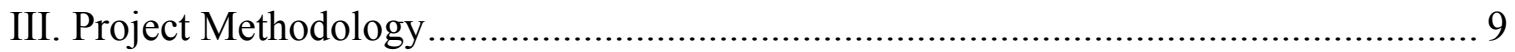

a. Educating the Collection's Owner...................................................................... 9

b. Preparation of the Environment......................................................................... 10

c. Organizing the Physical Collection ................................................................... 12

d. Rehousing: Glass Plate Negatives .................................................................. 15

e. Rehousing: Photographic Albums ...................................................................... 19

f. Digitization: Production ................................................................................. 20

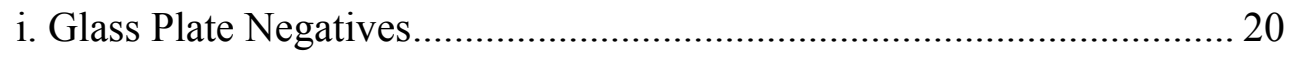

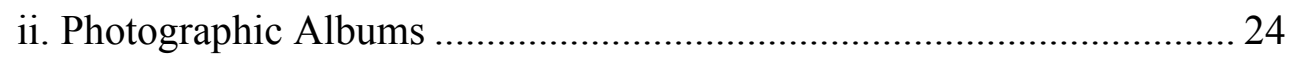

g. Digitization: Post-Production ......................................................................... 27

h. The Digital Database …………………………………................................... 29

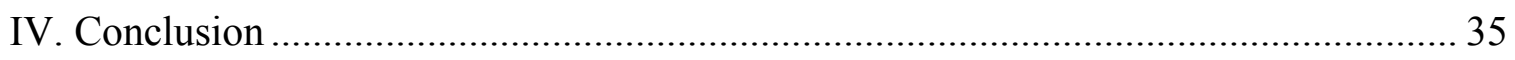

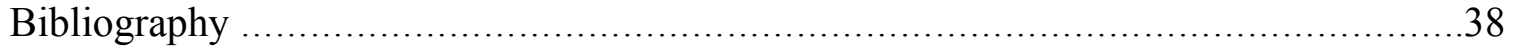




\section{LIST OF TABLES}

Table 1. Collected data from the Hobo Data Logger. ……............................................... 12

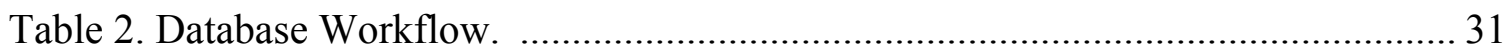

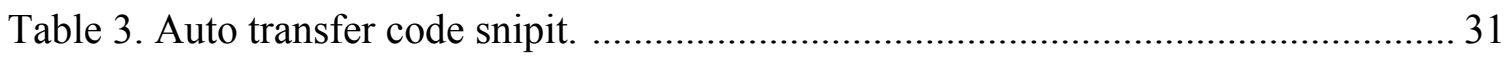

Table 4. Breakdown of accession number. ................................................................. 32

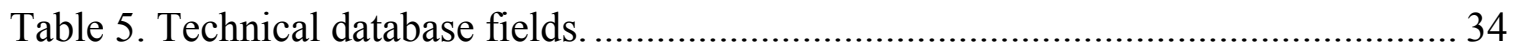




\section{LIST OF ILLUSTRATIONS}

Figure 1. Original housing for glass plate negatives. ................................................. 10

Figure 2. Data Logger (Onset Hobo MX1101). ............................................................ 11

Figure 3. Organization of glass plate negatives. ..................................................... 14

Figure 4. Excel spreadsheet for cataloguing. ................................................................. 14

Figure 5. Four-flap enclosure. .............................................................................. 15

Figure 6. Suspension box, interior view. ................................................................ 17

Figure 7. Sink mat for broken glass plate. .............................................................. 18

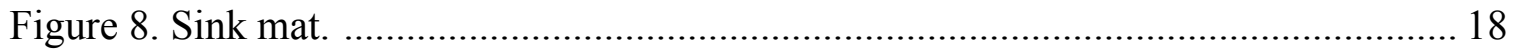

Figure 9. Four-flap enclosure, frontal view. ........................................................... 19

Figure 10. Photographic album, detail. .................................................................. 20

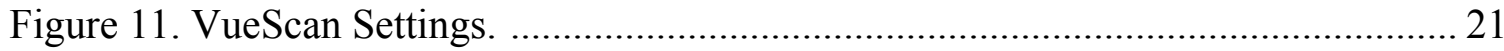

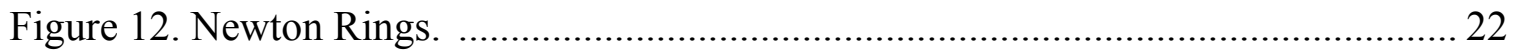

Figure 13. Glass plate negative on portable lightbox. ………………………………. 23

Figure 14. Lighting set-up for photo-documentation. ……………………………….... 25

Figure 15. Photographic album with a colour checker and gray scale card. ................... 25

Figure 16. Silver mirroring, detail. .......................................................................... 26

Figure 17. View of glass plate negative, documented with DSLR. ………..................... 28

Figure 18. View of glass plate negative, inverted. …………………………………..... 28

Figure 19. View of photographic album spread, digitally retouched. ............................ 28

Figure 20. Sample record in File Maker Pro. ................................................................. 30 


\section{INTRODUCTION}

Most generally accepted protocols for photographic preservation are institutionally based and developed. The goal for this project was to relate and apply these standards to a private collection of family photographs. I recognize that a 'collection' is often driven by a mandate and is usually created through active connoisseurship, searching for particular materials and/or objects that fulfill the intent of the mandate. This differs from a 'collection' of family-oriented memorabilia that was passively accumulated/inherited. Throughout this thesis, I use the term 'collection' to refer to this latter definition of the assemblage of objects and photographs. The need for the preservation of a collection is not solely dependent on its method of acquisition.

For this thesis, I focused on approximately 250 glass plate negatives and four corresponding albums, within a larger family collection, belonging to Michina Pope. The images were captured in Italy and date back to 1899. They depict Pope's ancestors, interiors of their homes, and surrounding landscapes. Over time, Pope transported these objects from Italy to her home in Toronto, Canada, on multiple trips and in no particular order. When I first encountered the collection, the glass plate negatives were haphazardly contained in a cardboard box and the photographic albums were sitting underneath a coffee table.

My practical thesis describes the development of organizing, preserving and digitizing the objects within Michina Pope's private family collection. Often, in private collections, each work exists in its own intellectual space. However, there is a thread connecting images and objects within a family collection that needs to be addressed and the owner of the collection has a critical role throughout this process. It was Pope's intent to actively participate, alongside myself, her consultant, in the preservation decisions and their implementation. The collaborative relationship between the owner and the consultant resulted in a customized approach to accessing the collection, intellectually, physically, and digitally. By helping one private collector care for her family's sensitive photographic materials, I hope to set a precedent for others who recognize the need for future generations to similarly experience their family collection. 


\section{LITERATURE REVIEW}

Before making any final decisions on the practical preservation of the collection, it was necessary to review existing literature on working with glass plate negatives and photographic albums. The following review of literature is comprised of four distinct sections referencing the following: the deterioration and preservation of glass plate negatives, the deterioration and preservation of photographic albums, the digitization of glass plate negatives and photographic albums and cataloguing methods for an archival collection.

\section{a. Deterioration and Preservation of Glass Plate Negatives}

Maria Fernanda Valverde's paper, "Photographic Negatives: Nature and Evolution of Processes," was published during her Advanced Residency Program in Photograph Conservation at the George Eastman House in 2005. This paper creates a timeline for a variety of negatives, including specific information on the manufacturing and processing of glass plate negatives. ${ }^{1}$ This text offered a better understanding of causes for deterioration and, therefore, allowed me to make educated decisions on preserving this particular collection.

A photograph conservator at the Art Gallery of Ontario, Katharine Whitman, wrote a paper in 2007 titled, "The History and Conservation of Glass Supported Photographs," discussing the history of glass plate negatives and the causes of deterioration. Through eleven case studies, Whitman demonstrates preservation and storage techniques for glass plate negatives, which was useful to me for developing a rehousing plan. ${ }^{2}$

Restaurator, the only international periodical that exclusively specializes in the conservation of library and archive materials, published "Glass Plate Negatives: Preservation and Restoration" in 1986. This article, written by three French photographic conservators, Françoise Flieder, Chantal Garnier, and Martine Gillet, provides a broad

\footnotetext{
${ }^{1}$ María Fernanda Valverde, "Photographic Negatives: Nature and Evolution of Processes" (Advanced

${ }^{2}$ Katharine Whitman, “The History and Conservation of Glass Supported Photographs" (Advanced Residency Program, George Eastman House, 2007.)
} 
overview of glass plate negatives and general conservation techniques. ${ }^{3}$ This document provided additional information for me to consider regarding the relationship between conservation and preservation.

Dee Psaila, Manager of Digitization and Operations at the Archives of Ontario, wrote "Design and Materials for Photographic Housing," as her Masters thesis in 2006. It includes a thorough material list, with detailed instructions and illustrations for constructing custom housings for different photographic materials. She compares photographic collections of five cultural institutions in North America and organizes the collected data by photographic type to help identify the most appropriate housings for each photographic material. ${ }^{4}$ This document was extremely helpful to me in devising practical housing solutions, especially for glass plate negatives, through its clear language and visual diagrams.

A pamphlet from the Canadian Conservation Institute, originally published in 1986, "Care of Black and White Photographic Glass Plate Negatives," offers a broad overview of the process, preservation and storage suggestions, as well as handling guidelines for glass plate negatives. It also includes suppliers of general conservation materials in both Canada and the United States. ${ }^{5}$ This resource proved helpful by outlining key details to relay to the owners of a private collection in order for them to better understand the importance of caring for their glass plate negative collection.

This selection of literature describes established conservation techniques applicable to glass plate negatives. Resources, such as local supplier lists, should help in executing the rehousing portion of this project. The multiple case studies, guidelines, and suggestions found in these publications provide a basis for understanding and preserving the glass plate negatives in Pope's collection.

\footnotetext{
${ }^{3}$ Françoise Flieder, Chantal Garnier, Martine Gillet, “Glass Plate Negatives: Preservation and Restoration" (Restaurator 7, no. 2, 1989), 49-80.

${ }^{4}$ Denise Psaila, "Design and Materials for Photographic Housing” (Master's thesis, Ryerson University, 2006.)

${ }^{5}$ Klaus Hendricks, "Care of Black and White Photographic Glass Plate Negatives" (CCI Notes 16.2. Ottawa: Canadian Conservation Institute, 1995.) Accessed 31 May 2015. http://canada.pch.gc.ca/eng/1439925171071.
} 


\section{b. Deterioration and Preservation of Photographic Albums}

The glass plate negatives in this collection were used to print the images in four early 20th century leather, silk, and paper photographic albums. The Library of Congress's "Preservation of Scrapbook and Album Formats," although essentially a digital version of a Preservation Basics information leaflet produced in 1991, helped me to prioritize preservation concerns, including environmental controls, physical storage and handling, as well as physical reformatting for photographic scrapbooks and albums. ${ }^{6}$ Similarly, "Preservation Options for Scrapbook and Album Formats," written in 1991 by Sherelyn Ogden, the Head of Conservation at the Minnesota Historical Society, introduces several different types of deterioration found in scrapbooks and albums as well as considerations for treatment options. The information provided was specifically useful in analyzing Pope's albums' individual elements as well as their artifactual integrity. ${ }^{7}$

The Interim Report on the Harry Ransom Humanities Research Center (HRHRC) Photographic Album Survey (1999) addresses the preservation and conservation of 250 photographic albums. The various papers helped me comprehend the physical structural elements of each photographic album. The series begins with a paper by Olivia Primanis, the Chief Book Conservator at the Harry Ransom Center titled, "Nineteenth Century Photograph Albums: Structure, Condition and Treatments" which presents potential conservation and stabilization treatments, according to different album types. ${ }^{8}$ "Photographs in Albums: Observations, Treatments, Comments and Some Survey Results" by Barbara Brown, the Head of Photograph Conservation at the HRHRC, supplements Primanis' paper by further identifying treatments and housing options,

\footnotetext{
${ }^{6}$ Barbara Zucker, "Preservation of Scrapbooks and Albums" (Preservation Basics: A National Cooperative Information Project, Leaflet no. 1. Washington, D.C.: Library of Congress, 1991.) Accessed 07 October 2015. http://www.loc.gov/preservation/care/scrapbk.html.

${ }^{7}$ Sherelyn Ogden, "Preservation Options for Scrapbook and Album Formats" (The Book and Paper Group Annual, Vol. 10, 1991.) Accessed 24 September 2015. http://cool.conservationus.org/coolaic/sg/bpg/annual/v10/bp1014.html.

${ }^{8}$ Olivia Primanis, "Nineteenth Century Photograph Albums: Structure, Condition, and Treatments" (Conservation of Scrapbooks and Albums. Postprints of the Book and Paper Group and Photographic Materials Group Joint Session at the 27th Annual Meeting of the American Institute for Conservation of Historic and Artistic Works. June 11, 1999. St. Louis, Missouri, 47-64. Washington: AIC, 2000.)
} 
according to the different types of damage found in photographic albums. ${ }^{9}$ In her paper, "Developing a Conservation Survey Database for Photograph Albums," Meg Brown, Special Collections Conservator and the Exhibits Coordinator for Duke University Libraries, identifies the challenges of surveying terminology and definition standardizations. ${ }^{10}$ She also compiles a Glossary of Terms with original and electronic survey forms, useful for documentation and further care of the collection of albums. ${ }^{11}$

This assemblage of literature creates a timeline of materials used in the construction of late-nineteenth and early-twentieth century photographic albums and scrapbooks. The innovative conservation techniques and questions of access play a critical role in determining how to best preserve the photographic albums in Pope's collection.

\section{c. Digitization of Glass Plate Negatives and Photographic Albums}

As part of the preservation process, one of the goals is to minimize the handling of the photographic objects in this collection. Therefore, it is necessary to digitize both the glass plate negatives and photographic albums. Kim Knox Norman, a member of the Collections Conservation team at Emory University's Preservation Office wrote an article, "Preservation of Emory University's African American Scrapbook Collection," published in Archival Products News in 2014. This article describes the conservation and digitization of 34 scrapbooks, demonstrating the combined efforts of the conservation and

\footnotetext{
${ }^{9}$ Barbara Brown, "Photographs in Albums: Observations, Treatments Comments, and Some Survey Results" (In Conservation of Scrapbooks and Albums. Postprints of the Book and Paper Group and Photographic Materials Group Joint Session at the 27th Annual Meeting of the American Institute for Conservation of Historic and Artistic Works. June 11, 1999. St. Louis, Missouri, 69-79. Washington: AIC, 2000.)

${ }^{10}$ Meg Brown, "Developing a Conservation Survey Database for Photograph Albums" (Conservation of Scrapbooks and Albums. Postprints of the Book and Paper Group and Photographic Materials Group Joint Session at the 27th Annual Meeting of the American Institute for Conservation of Historic and Artistic Works. June 11, 1999. St. Louis, Missouri, 65-69. Washington: AIC, 2000.)

${ }^{11}$ Meg Brown, "Glossary of Terms for the Photograph Album Survey." (Conservation of Scrapbooks and Albums. Postprints of the Book and Paper Group and Photographic Materials Group Joint Session at the 27th Annual Meeting of the American Institute for Conservation of Historic and Artistic Works. June 11, 1999. St. Louis, Missouri, 85-92. Washington: AIC, 2000.)
} 
imaging staff to maintain the "scrapbook experience." 12 Through various techniques customized to each scrapbook, their work further reinforced my desire to not only preserve the photographs but also maintain the original scrapbooks as objects.

Another article published in Archival Products News in 2015, "Preserving Vaudeville and Early-Film History at the University of Iowa", was written by Bethany Davis, the Digital Processing Coordinator Librarian at The University of Iowa. This article outlines the early stages of the stabilization, rehousing, as well as the digitization of 150 scrapbooks. It mentions various difficulties when other materials are found within the scrapbooks, such as newspaper clippings. ${ }^{13}$ This article also includes images of custom book cradles that can be useful for photographing the scrapbooks and heightened my awareness of possible challenges that might arise during the documentation process. The Library of Congress conducted a case study of the of the Sergei Mikhailovich Prokudin-Gorskii Collection in the Fall of 2000, portions of which were subsequently published online. The study details the various digitization methods used for both the glass plate negatives and albums of the collection. This resource outlines the resolutions and file formats that were used for both the glass plate negatives and the albums. ${ }^{14}$ It proved to be an extremely valuable tool in determining the quality necessary for the different purposes of the collection. However, while the details for files were helpful, there are neither sufficient illustrative images of the working operations nor is there a list of the equipment used so, as a result, further research was necessary.

There are many published approaches to digitizing photographic albums that can provide a basis for documenting albums for my thesis. However, there are limited resources dedicated to digitizing glass plate negatives. As a result, I relied on the

\footnotetext{
${ }^{12}$ Kim Knox Norman, "Preservation of Emory University's African American Scrapbook Collection" (Archival Products NEWS 17 (3), 2012.) Accessed 25 September 2015. http://www.archival.com/newsletters/apnewsvol17no3.pdf

${ }^{13}$ Bethany Davis, "Preserving Vaudeville and Early Film History at the University of Iowa" (Archival Products NEWS 19 (2), 2015.) Accessed 25 September 2015. http://www.archival.com/newsletters/apnewsvol19no2.pdf.

${ }^{14}$ Library of Congress, "Prokudin Gorskii Collection: Digitizing the Collection - Prints \& Photographs Online Catalogue.” Accessed 07 October 2015. http://www.loc.gov/pictures/collection/prok/digitizing.html.
} 
available case studies for guidance in the digitization process. My research on various methods may contribute new information to this field and is documented within the subsection of "Digitization: Production" entitled, "Glass Plate Negatives."

\section{d. Cataloguing Methods for an Archival Collection}

Since both the owner and her collection currently reside in Toronto, I have referenced Canadian standards for cataloguing in this section to ensure that Pope's collection is compatible with most other public collections and archives in Canada. Rules for Archival Description (RAD), formulated in 1990 and revised in 2008, is a readily accessible PDF, presenting standards that apply to archival material in Canada.

However, the manual, comprised of almost 700 pages, was not created with the intent of being read from cover to cover. As a result, the Canadian Council of Archives created a condensed, more approachable document, known as Basic RAD. ${ }^{15}$ This 'basic' guide was not created as a replacement for the first document but rather, Basic RAD is meant as a counterpart to RAD. Basic RAD's introduction contains fundamental information regarding archival descriptions, along with detailed descriptions and sample entries. ${ }^{16}$ My approach to structuring Pope's collection is based on this document, according to its content and the related notions of 'fonds', 'series', and 'items'.

Another resource that provides Canadian standards for data content is Cataloguing Cultural Objects: A Guide to Describing Cultural Works and Their Images. Multiple editors created this resource in 2006 through Cataloguing Cultural Objects (CCO). This resource is intended as a manual for both the planning and implementation of database entry that maintains compatibility with local cataloguing practices. ${ }^{17}$ This manual conveniently highlights consistencies through various metadata elements,

\footnotetext{
${ }^{15}$ Rules for Archival Description (Ottawa: Canadian Council of Archives, 2008.) Accessed 07 October 2015. http://www.cdncouncilarchives.ca/RAD/RADComplete_July2008.pdf.

${ }^{16}$ Jeff O'Brien, Basic RAD: An Introduction to the Preparation of Fonds-and Series-level Descriptions Using the Rules for Archival Description (Regina: The Saskatchewan Council of Archives, 1997.) Accessed 07 October 2015. http://scaa.sk.ca/rad/rad4.pdf.

${ }^{17}$ Cataloguing Cultural Objects: A Guide to Describing Cultural Works and Their Images (Chicago: American Library Association, 2006.) Accessed 24 September 2015. http://personal.sirma.bg/vladimir/cco/Cataloging_Cultural_Objects.pdf.
} 
stressing access through multiple channels. Due to the length and scope of the overall document, it is preferable to reference the individual chapters. Although the chapters are in-depth, they are accessible through the inclusion of multiple examples, such as data input for records, which was helpful when forming the database for the collection.

The gathered materials and manuals in this section will help ensure the collection's compatibility with other Canadian collections of photographs and artifacts through the standardization of the cataloguing process. I believe the location and context in which Pope's objects are currently located is relevant to the cataloguing methodology. By focusing on a particular standard for cataloguing methods, I was able to appreciate the importance of certain fields for application in this particular project.

\section{Summary}

Through the histories offered in the selected literature I have cited here, the importance of the preservation of these photographic objects is emphasized, which contributes to the strengthening of both the rehousing and digitization aspects of my thesis. As well, the referenced cataloguing manuals establish the standards necessary for this collection to be compatible with other archives in Canada. As a result of this integration, the collection will benefit in the future from greater accessibility. Finally, through my research, the absence of available manuals and subsequent standards for private collections became apparent. One guideline that I found is titled, "Preserving Your Family Photographs," published by the Cornell University Library Department of Preservation and Conservation in 2001. ${ }^{18}$ This document serves as a good introductory resource but supplementation with further research is needed. This emphasized the need to create a more detailed resource that is customizable for specific collections, allowing each collector to properly care for and manage their photographic collections.

\footnotetext{
${ }^{18}$ Preserving Your Family Photographs, (Cornell University Library Department of Preservation and Conservation, 2001.) Accessed 31 May 2016. https://www.library.cornell.edu/preservation/brochure/Family\%20Photos\%20Text\%2001.pdf.
} 


\section{PROJECT METHODOLOGY}

\section{a. Educating the Collection's Owner}

This project began with a discussion with the owner of the collection, Michina Pope. Formerly involved in the art world as a Jewelry Specialist for Sotheby's, Pope is keenly aware of the importance of preserving her family's archive and is eager to devote the time and effort to do so. We discussed the importance of the objects to her, her family and her Italian history. It was critical for me to understand her motivation for preserving these images, as it would help guide my approach to facilitating the management of the collection.

I, in return, educated Pope about the significance of her photographic inheritance. I directed her to the Image Permanence Institute's online resource, Graphics Atlas, which displays examples of different photographic processes from the inception of photography to modern inkjet prints. This website gave her a broad overview of the history of photographic materials and helped contextualize her family's collection of glass plate negatives and albums.

After surveying the inherited objects by type, I established a hierarchy of importance, based on the following main two criteria: the overall physical condition of the objects and the subject matter of the image. I determined that the glass plate negatives, haphazardly contained in a cardboard box, had the greatest need for organization and care. Furthermore, these negatives are the basis for prints found in four of the photographic family albums. Digitization would hopefully reveal more details that could not be easily seen in the glass plate negatives or in the faded prints. We agreed upon a timeline, along with an estimate of costs for archival materials, equipment, and software. 


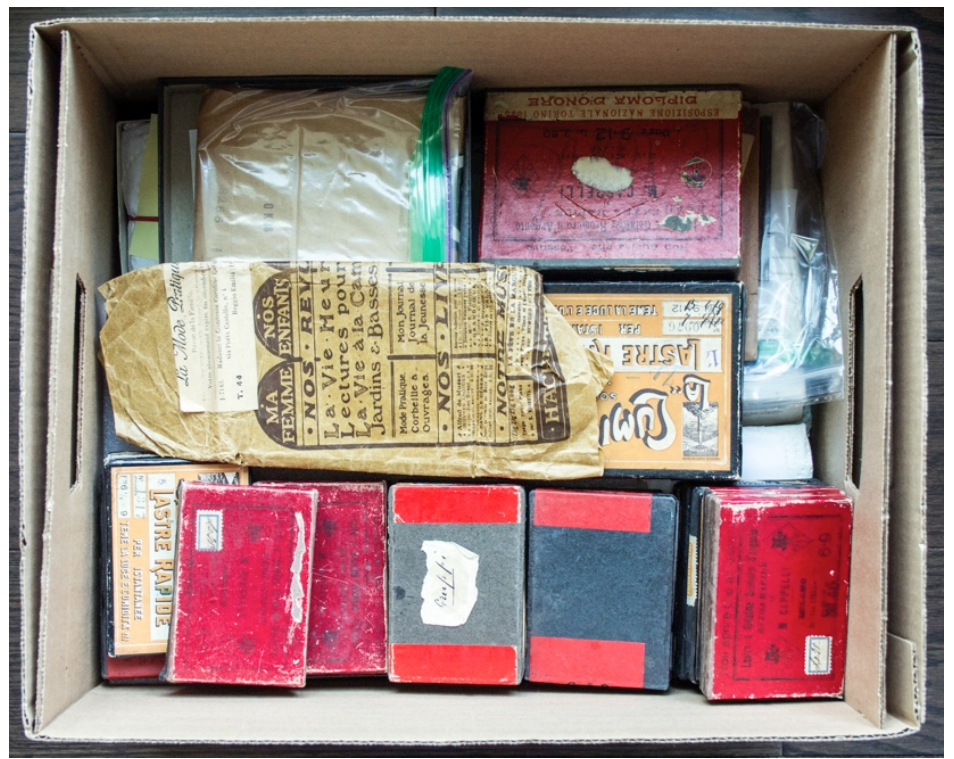

Figure 1. Original housing for glass plate negatives.

\section{b. Preparation of the Environment}

Through further discussion of the fragile nature of the photographic processes found in her collection, the owner better understood the need for proper handling of the objects. My first challenge was to translate these abstract concepts into applicable, achievable practices. I chose to focus on three basic aspects: handling, work space, and storage environment. Before physically handling the collection, the difference between working with private collections and those of larger institutions became apparent. If we had been working within an established institution, there would have been a proper environment in which to work and pre-existing protocols to follow. However, with a private collection, one has to be resourceful and tailor the procedures and adapt accordingly to the existing environment.

The first implemented protocol was to wear gloves when handling the objects. I showed Pope the differences between cotton and nitrile gloves, how to properly put them on and how to handle the objects while wearing them. Nitrile gloves are preferable to cotton, as they allow for a better grip of the plate, and will have less of a likelihood of catching on the emulsion, causing peeling. Gloves prevent dirt and oil from transferring to the object as well as protect the operator from the plate's potentially sharp edges. This 
aspect of the project was superficially understood by Pope, but often was also the most difficult for her to follow through with, as the use and feel of gloves was quite foreign to her. However, even the most obvious and mundane details should not be overlooked, as they are a critical part of the preservation process.

The second priority was to establish a clean and safe work environment in Pope's condominium. Although less than ideal, the best space was a countertop near the kitchen, which was thoroughly cleaned and covered with a foam pad before each work session. The working environment is just as important as the overall storage environment and while there were certain measures that could be taken, there are many that are, for the most part, not visible to the naked eye. This includes the control of the temperature and humidity of the overall work and storage environment. While the objects are currently in a few locations in her condo, Pope purchased an Onset Hobo MX1101 Bluetooth Low Energy Temperature/Relative Humidity Data logger in order to get a better sense of the localized conditions. She placed the logger in close proximity to where the objects are housed, and leaves it there, untouched, to gather information. After discussing the ideal numbers for temperature and humidity for her collection, Pope has been able to see, first hand, how simply adjusting the thermostat can affect the overall numbers. Even though she currently has limited control of the environment, obtaining a data logger has offered Pope a better awareness of the overall picture in terms of long-term preservation.

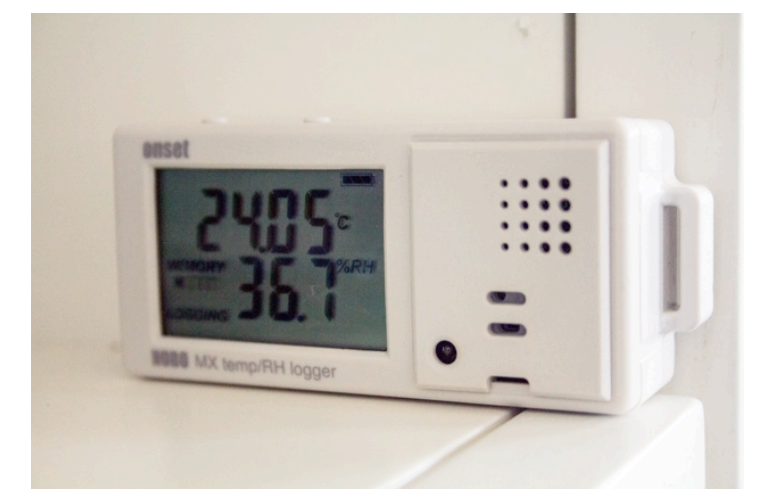

Figure 2. Data Logger (Onset Hobo MX1101). 
Table 1. Collected data from the Hobo Data Logger.

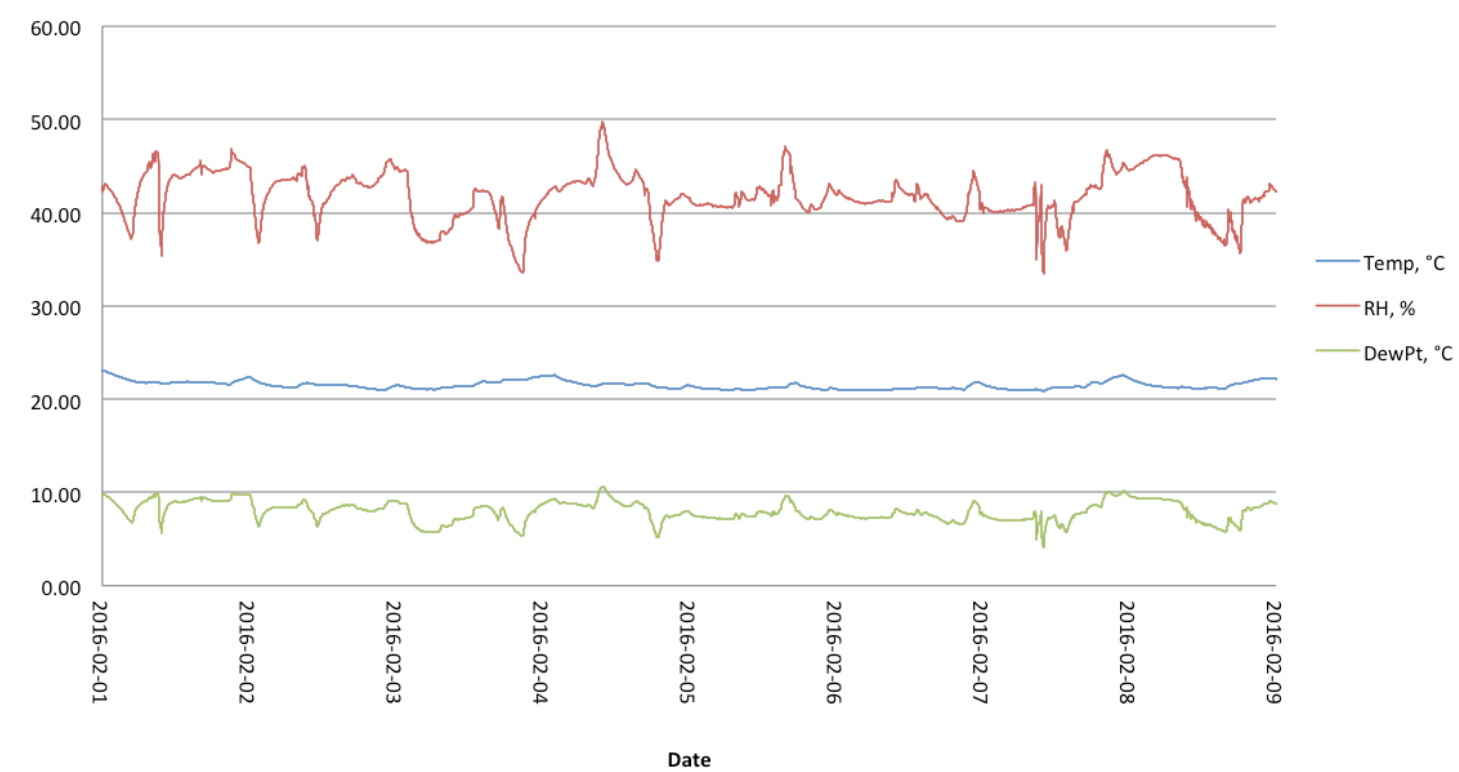

However, a recurring issue is that Pope forgets to view and download the information gathered. To address this, I created a predetermined schedule, with notifications in her personal calendar that prompt her to view and download the device's informational graphs from her phone as Excel spreadsheets. We review this information together on a regular basis. Ultimately, the goal is for Pope to independently analyze the data and recognize any aberrations.

\section{c. Organizing the Physical Collection}

As the owner, author and manager of this private collection, Pope is concerned about her on-going access to, and control of, the content. It is important for her to personally access the collection in an easy manner with the ability to choose which images and information to share with others. In fact, given that the author of the collection still has a hand in the reorganization and preservation, the approach may sometimes be less objective. With private collections, it is imperative to remember that the collection owner maintains full control over the information that is shared. When 
working with amateurs, there is a dual nature to a consultant's role - a sense of responsibility to preserve the objects while respecting the privacy of the collection owner and his/her collection.

The next, and arguably the most important, step was to develop an organizational approach that satisfied Pope's expectations of being able to actively participate in, access, and maintain her collection. As objects were brought over from Italy to Canada in no particular order, it was less relevant to maintain the original order. In fact, many of the original objects were displaced into different housings. For example, the glass plate negative boxes no longer held their original glass plates. As a result, I chose to catalogue the glass plates and consider the boxes as separate yet associated objects.

Originally the collection was partially organized in a haphazard manner that was tailored to one person, both physically and intellectually in terms of access. It was important for me to reorganize the collection in the most organic yet rational way, creating as many access points into the collection as possible. ${ }^{19}$ The most efficient way to organize the physical objects was first by object type, then by size, and finally by chronology. This arrangement allows for an easier correlation between all images in the collection, forming a more succinct family timeline.

We began organizing the collection of glass plate negatives by carefully removing the plates from the boxes and arranging them in piles, separating the plates temporarily with a sheet of paper to protect their emulsion and glass surface. We rearranged the piles based on their dates, which were discovered through close examination of other family images and documents. As the appropriate date for each plate was discovered, it was noted on the paper, along with an object number. If an image printed from the glass plate was found in one or more of the photographic albums, an additional corresponding coloured note(s) with the page number(s) of the album was added to the sheet of paper.

\footnotetext{
${ }^{19}$ Charlene Heath, conversation with author, 29 June 2016.
} 


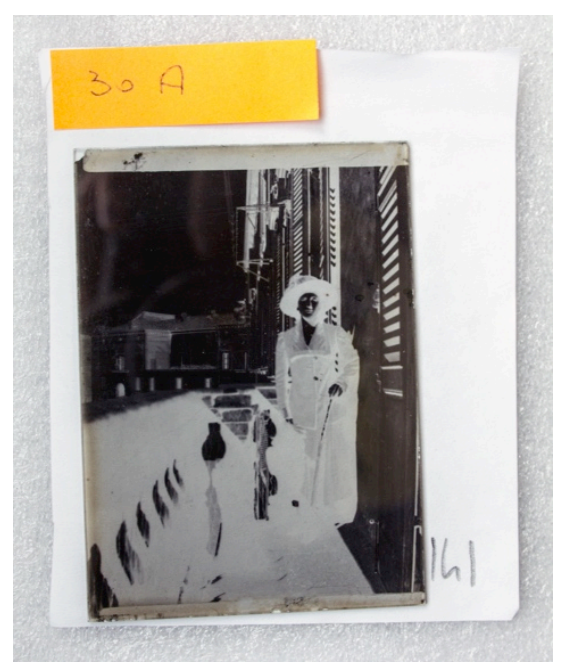

Figure 3. Organization of glass plate negatives.

As expected, there were a few plates that could not be definitively dated. As a result, these plates could not be placed in chronological order when object numbers were assigned. I determined that these plates would be scanned first with the hopes of extracting more information visually from the digital copy. Ideally, I would have organized the plates based on their chronological date as well as their physical size. Unfortunately, scanning was only partially successful and plates that would otherwise have been housed together, based on their dates, had to be housed separately, due to their difference in size. To assemble this information in a cohesive format, I created an Excel spreadsheet with the following columns: Object number, Descriptive Title, Display Date, Creator, Place of Creation, Medium, Measurements, Conservation notes, and one column for each of the four Albums.
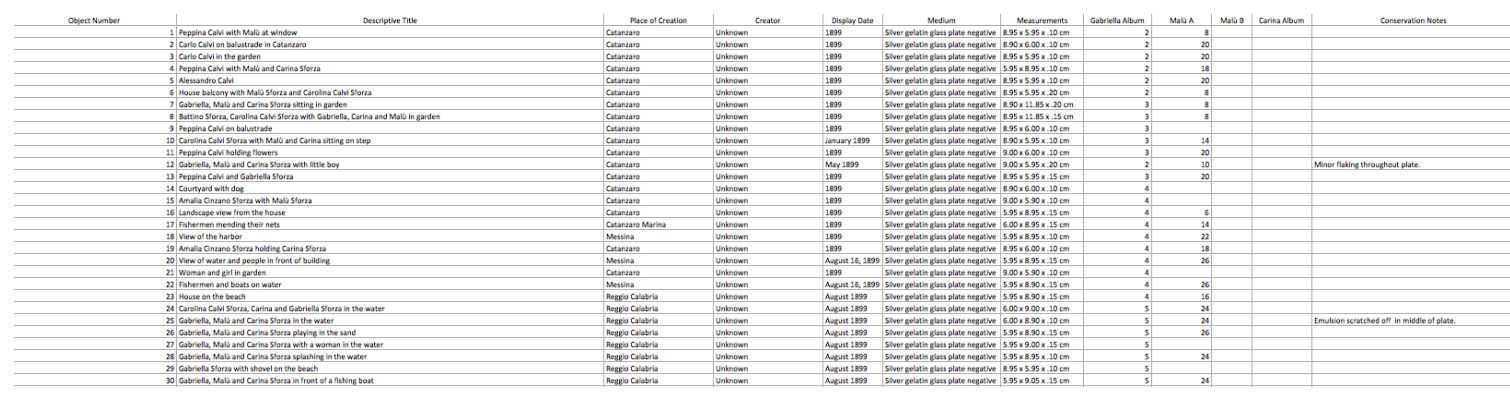

Figure 4. Excel spreadsheet for cataloguing. 


\section{d. Rehousing: Glass Plate Negatives}

The next step was to rehouse each glass plate. The primary concern was how to provide the most secure housing system with the least amount of handling. Time and financial resources were secondary concerns. Based on these factors, I decided that the best approach was to use a four-flap enclosure made of acid and lignin-free, unbuffered white stock with four flaps that fold towards the center. Each glass plate negative was placed in its own enclosure and then housed within a suspension box. I advised against an additional outer envelope, as it created more opportunities for mishandling.

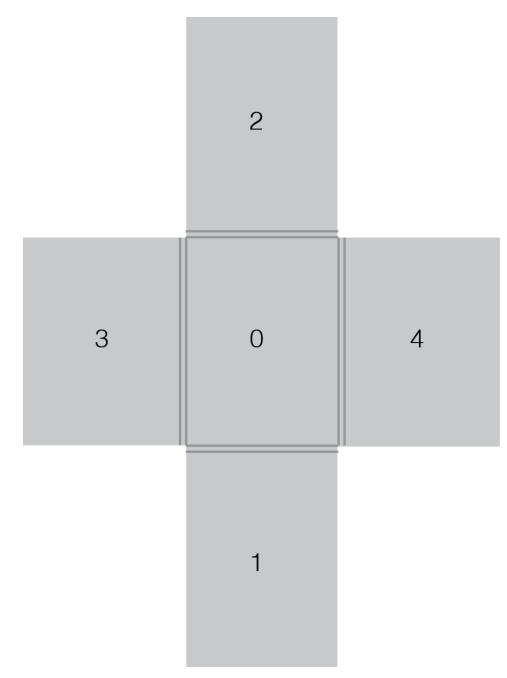

Figure 5. Four-flap enclosure.

The first challenge was the discovery that the majority of the glass plate negatives were of a size that did not match the standard sizes of enclosures available from most archival supply companies. As a result, I proposed three options for Michina's consideration. The first was to order pre-cut standard-sized enclosures, closest to the size of the plates. However, the extra space in the enclosure is not ideal, as it increases the possibility of friction. I consulted with Dee Psaila about the option of adding a small mat, to create padding and reduce friction within the enclosure. However, she advised against it as the adhesive on that mat could dislodge and possibly re-attach to the photographic plate. The second option was to order pre-cut, custom-sized enclosures. While this is the 
most archivally-preferred option, it is also the most costly. I contacted a few companies that create custom orders, but their cost was roughly four times the price of standardsized enclosures. The third option was to order archival paper to make the custom enclosures myself. This option is a more cost-effective way to achieve the same archival benefits as the second option; however; it is much more time consuming. Ultimately, we opted for the first approach, to order standard-size enclosures. For a few select plates, I cut these standard-size enclosures to better fit a smaller sized plate.

I ordered enclosures from both a Canadian company (Carr McLean) and an American company (University Products) and it is interesting to note that Pope preferred the latter, stating that they were easier to fold, resulting in a more aesthetically pleasing finished product. To ensure that Pope consistently and properly handled the plates, I devised an intuitive order to assemble the enclosures. The bottom flap was folded up first, to create a nesting for the plate, then the top, then the left flap and lastly the right. While the actual order of folding is less important, it is significant that the order remains the same throughout.

Once each plate was individually enclosed, the next task was to determine how best to store them. It is best to store the plates that are in relatively good condition in suspension boxes, stacked vertically on their longest edge. However, similar to matching the non-standard glass plate negatives with standard-sized enclosures, I was challenged to find suspension boxes that best fit these enclosures. I ordered the closest size available in suspension boxes and I created spacers out of archival mat board for extra padding, in order to reduce movement and friction within the box. Due to the fragility of the glass plates, it is important to pay attention to the overall weight and not overfill the box. However, it is also not ideal to have an excess number of boxes, making it inconvenient when locating the physical objects. I then labeled the front side of each box with the accession number and date range along with the words "caution - fragile - glass heavy."20

\footnotetext{
${ }^{20}$ Sarah S. Wagner and Miranda Martin, "How Do I House Glass Plate Negatives? (The U.S. National Archives and Records Administration, 18 June 2001.) Accessed 07 October 2015. http://www.archives.gov/preservation/storage/glass_plate_negatives.html.
} 


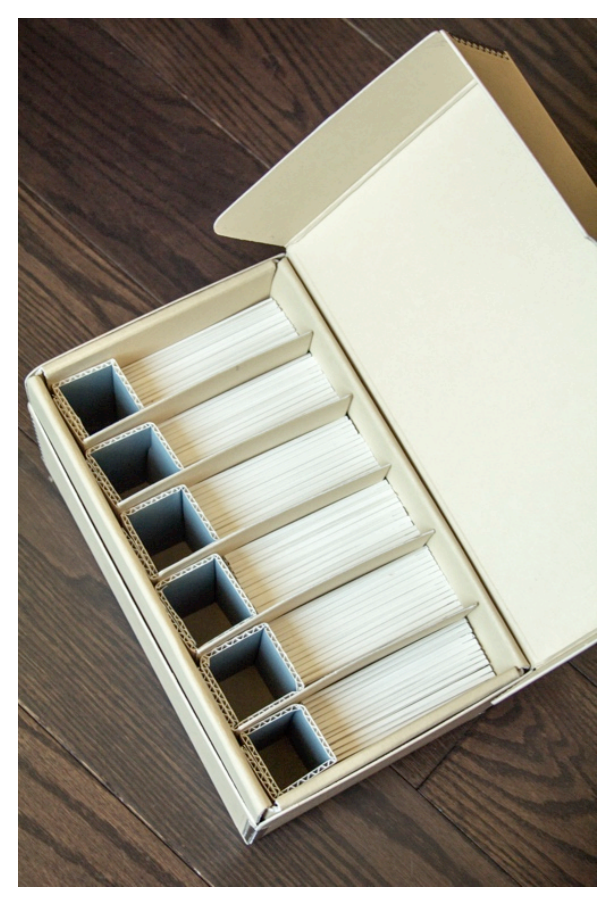

Figure 6. Suspension box, interior view.

There were a few plates that required more extensive housing due to their extensive fragility. I created a sink mat for any broken plate, with corrugated board as padding for the broken pieces. The plates with peeling emulsion were a bit more difficult. While I had originally considered sandwiching the loose emulsion with another piece of glass, Psaila pointed out that it would create more possibilities of torn or scratched emulsion, as well as create a potentially unsafe microenvironment, trapping moisture, etc. Furthermore, with plates that are more fragile, I needed to consider the feasibility of conservation work in the future. Psaila suggested treating the loose emulsion in a sink mat, placing the plate emulsion side up with a piece of acid free paper under the top lid of the sink mat. In cases like these, labeling the outside of the enclosure is an important indication of loose emulsion below. ${ }^{21}$ Furthermore, these sink mats are stacked horizontally (elevated no higher than five) and housed in a custom archival clamshell box, labeled "caution - broken glass negatives - heavy."22

\footnotetext{
${ }^{21}$ Dee Psaila, email to author, 7 June 2016.

${ }^{22}$ Mark Roosa, Care, Handling, and Storage of Photographs. (Paris: IFLA-PAC, 2004. 13-14.)
} 


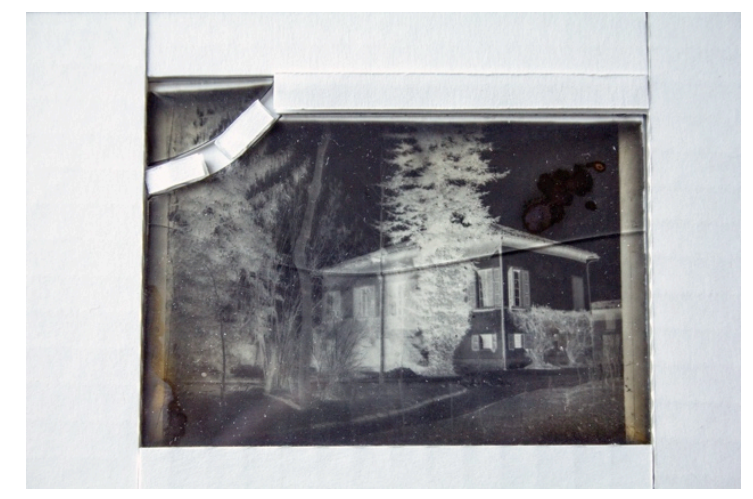

Figure 7. Sink mat for broken glass plate.

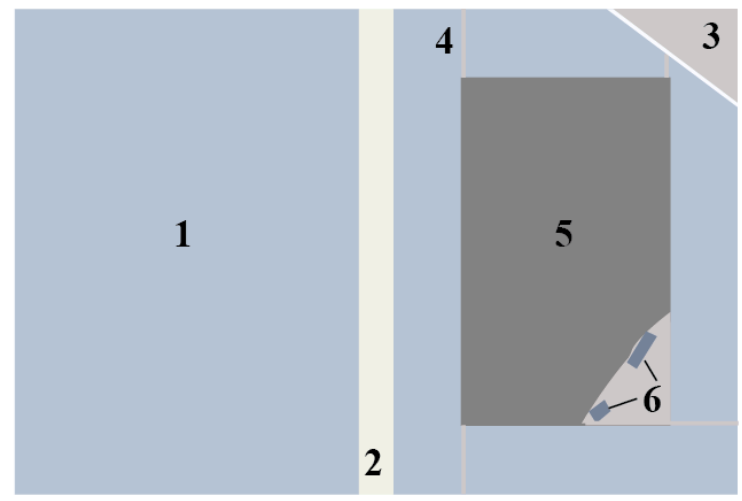

1. Cover; 2. Hinge tape; 3. Base; 4. Support pieces; 5. Negative; 6. Plugs

Figure 8. Sink mat.

In order to keep the plates as protected as possible, I discouraged any unnecessary handling of the objects. To help limit interaction with the plates themselves, I thought it prudent to include pertinent information on the outside of each enclosure. Initially, we wrote the object number, in pencil, in the top right. However, this number later became part of the accession number and was printed on archival labels, along with an inverted (positive) thumbnail image of the object. These labels, sized 2 x 3 inches, were placed on the front of the enclosures. In some cases the label is proportionally large in comparison to the enclosure; yet, it allows for a reasonably-sized thumbnail with a 14-point size Helvetica font for clearer viewing. 


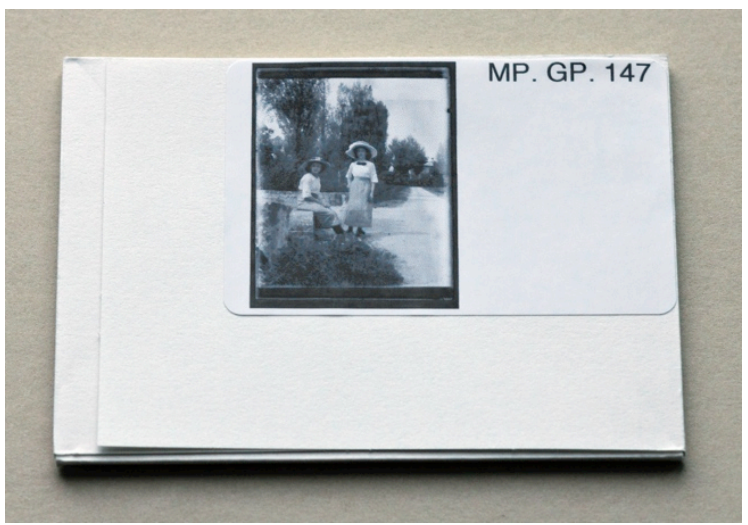

Figure 9. Four-flap enclosure, frontal view.

\section{e. Rehousing: Photographic Albums}

Prior to engaging me as a consultant, the collection's owner kept her photographic albums under her coffee table in her living room, where her guests could have unrestricted access to them. This contributed to their fragile condition and compromised their spines. Before addressing the preservation issues of the albums, I consulted with a few people, including a Toronto book conservator, Betsy Palmer Eldridge, who pointed out two main considerations for housing photographic albums: how often the albums would be accessed and where they would be stored. There would be less concern about access if a digitally produced copy of each album was made available. If not, there would be greater concern for the appearance of the housing if the albums were kept on open display. Based on Mark Roosa's suggestion in Care, Handling, and Storage of Photographs that "interleaving should be done judiciously because it adds bulk to an album and places undesirable stress on the binding," the initial decision was to forego any interleaving tissue. ${ }^{23}$ However, I have begun to re-evaluate this on a spread-by-spread basis. Until we can commit to a long-term housing solution, I loosely wrapped the albums in tissue paper and placed them flat in boxes, as a temporary measure of protection. I am currently experimenting with different materials and evaluating their benefits for a simple, yet effective and cost efficient solution for permanent housing. At this time, my preference is for creating custom, fitted enclosures for the albums.

\footnotetext{
${ }^{23}$ Mark Roosa, Care, Handling, and Storage of Photographs. (Paris: IFLA-PAC, 2004. 15.)
} 


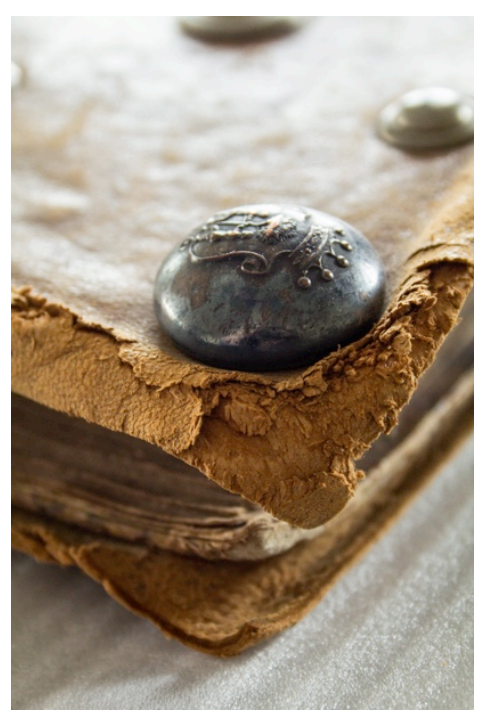

Figure 10. Photographic album, detail.

\section{f. Digitization: Production}

\section{i. Glass Plate Negatives}

As one of her original goals for this project, Pope wanted the ability to continue to care for her collection in the most consistent manner. I recognized that digitization would be an inevitable and integral part of the process. One of my earliest responsibilities as her consultant was to research the most reliable and consistent methods for digitization. After a thorough investigation of available options for digitizing the glass plates, I decided that using a flatbed scanner was the most efficient option. The Epson v800 was the most costeffective scanner capable of scanning larger negatives, made possible with its fully removable top. Although the Epson scanning software, included with the scanner, was adequate, I found VueScan software allowed greater control over the settings for scanning, resulting in more detailed images. Other advantages of VueScan include its reasonable cost, simple user interface, as well as its ability to save scan settings and to create different scanning profiles to help the owner standardize her methodology. My hope is to provide Pope with written guidelines in order to create a somewhat 'foolproof' system. 


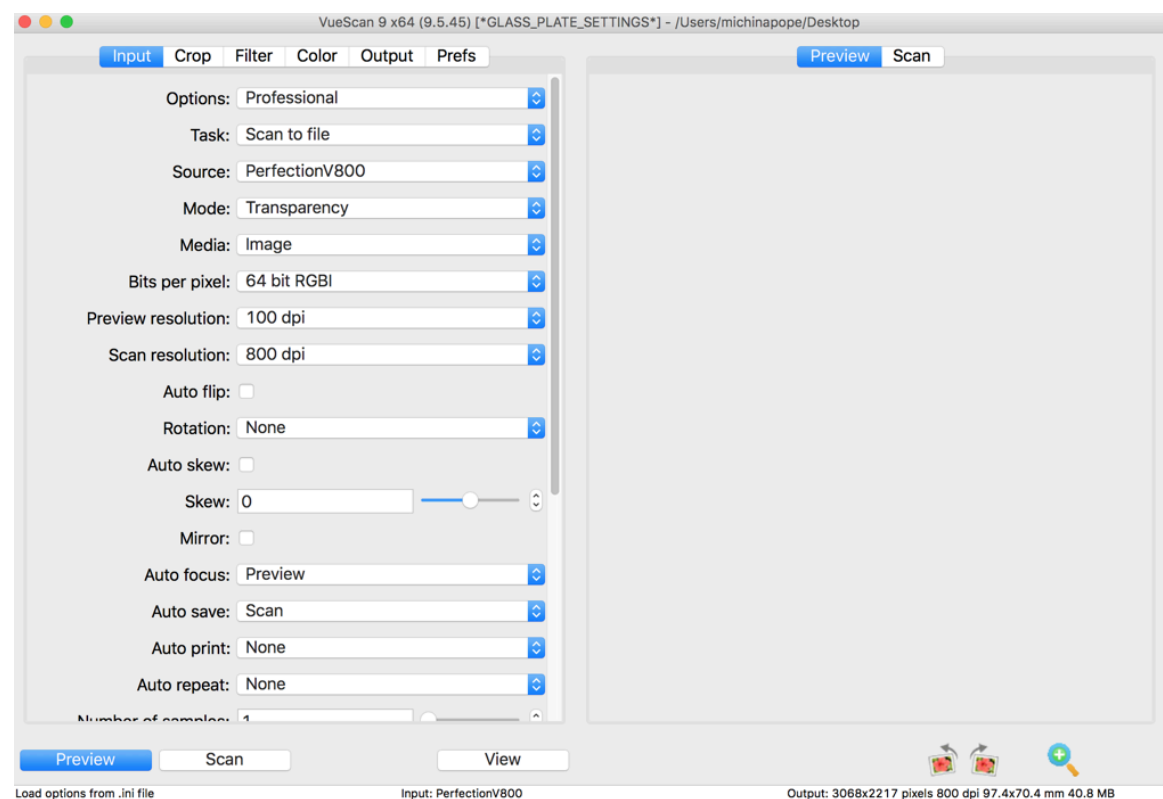

Figure 11. VueScan settings

In order to determine the proper scanning settings, I researched archival standards and determined which could be realistically applied to this private collection, keeping in mind time, expenses, and the owner's desired outcome. I initially scanned the plates for high resolution raw (dng) files with 48-bit RGB color but later revised the scanning settings to 64-bit RGBI to achieve greater detail. ${ }^{24}$ However, because of the cost and noncompliance with 20th century materials and limited number of color checkers available for transparent materials, one was not purchased for this project. This means that while one could potentially refer back to the original scan if there were conservation issues in the future, such as discoloration and fading, the original scanned color would only provide a hint of the object's previous state. The main reasons for digitization were to obtain detailed and sharp scans and to enhance the accessibility of images. In fact, the collection's owner placed greater importance on the content of the image than the object itself. As a preservation consultant, I was challenged to come up with a viable solution that could address both perspectives. My solution was to create aesthetically pleasing

\footnotetext{
${ }^{24}$ This decision was based in part on a conversation with Mike Robinson, a daguerreotype specialist and proprietor of the Century Darkroom, Toronto, on March 18, 2016.
} 
(edited) jpeg and tiff files from high resolution (unedited) raw files that meet industry standards. This allows the raw files to remain untouched as a preservation copy. This work flow is discussed further in the next section, "Digitization: Post-Production."

I carefully prepared both the plates and the equipment before and during the scanning process. We always held each plate by its two opposite edges and avoided stacking them at all costs. To avoid any unnecessary pressure on the plates, I instructed Michina to write any information on the enclosures before placing the plates inside. We wiped each plate's glossy, non-emulsion side with a microfiber cloth but used a handheld air blower to clean the emulsion side, taking care to not dislodge any emulsion or exacerbate any peeling or flaking. Between each scan, I wiped the scanning bed with another microfiber cloth to eliminate dust and dirt.

I scanned the plates with the emulsion side down (shiny side up) for best scanning resolution, taking extreme care to not let the plate slide while in place. One of the main issues with scanning glass plates is the focus of the scanning bed. Due to the materiality of the object, some issues could potentially occur such as Newton's Rings ${ }^{25}$ as well as the risk of damaging the plate and/or scanning bed.

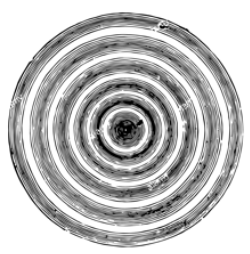

Figure 12. Newton Rings.

As precautions, I first experimented with placing a sheet of acetate/mylar on the scanning bed as a buffer between the glass of the scanner and the glass plate. However, due to the thickness of the glass and another material in between the scanner and the object, both focus and Newton Rings were sometimes an issue. I was able to borrow antiNewton Ring glass from the Ryerson School of Image Arts but, once again, I found that

\footnotetext{
${ }^{25}$ A phenomenon that occurs when there is a reflection of light between two surfaces and results in an interference ring-like pattern.
} 
the focus was a bit obstructed. I then attempted to remove any buffers directly between the plate and scanning bed by placing small foam pads on the outer of the scanning bed in order to raise the hood of the scanner, reducing pressure to the glass plate. Regardless, because most of the plates were relatively thin, and the hood of the scanner could be raised and placed over the glass plate negative, this was less of a concern. Ironically, after all of these experiments, I decided to scan the glass plates directly on the scanning bed without any buffers on the scanner. Furthermore, simple decisions such as scanning with a 100-pixel dpi preview saved time throughout the process, as high-resolution previews take time and are not necessary for the initial cropping.

However, there are a number of objects that I do not recommend digitizing with a scanner. For instance, a number of the plates were too fragile to be put on a scanning bed due to peeling emulsion. In these cases, we utilized a portable light box/tablet that we purchased as a light source for photographing. As well it served as a safer way to view the glass plate negatives. The setup was similar to working with a copy stand, with the light box as the base and the camera placed parallel to it above. Furthermore, when possible, controlling the ambient light of the room produced better documentation of the plates. When raking light is limited, the lightbox, underneath the glass plate negative, is the stronger light source, providing sharper, better-contrast images as a result.

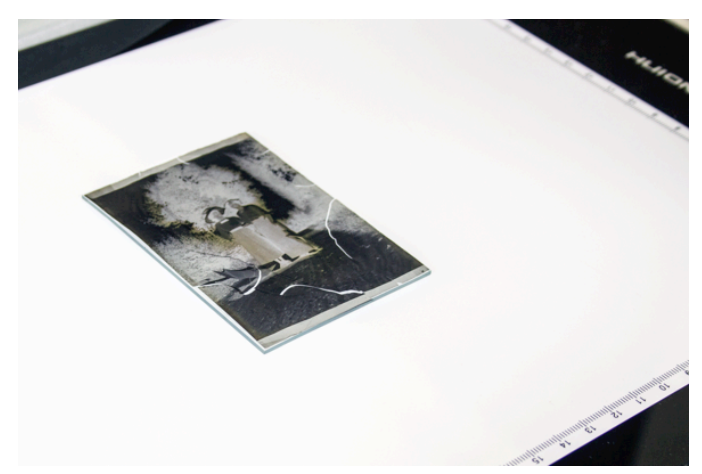

Figure 13. Glass plate negative on portable lightbox. 


\section{ii. Photographic Albums}

A similar process to digitizing the more fragile glass plates was used for digitizing the photographic albums. In this case, the primary concern was to avoid overstressing the album's spine. I strongly emphasized this concern to the owner, since it applied to other objects in her collection as well. I discussed the option of creating an in-home copy stand with two even light sources (at roughly a $20^{\circ}$ angle). While the camera body is parallel to the albums, the lens is perpendicular (at right angles) to the album. However, as it wouldn't be a permanent set up and only used for a few objects, we determined that it would be best to outsource this part of the digitization.

I received permission to photograph the albums with the copy stand and camera at the Ryerson Image Centre. In the makeshift studio at the Ryerson Image Centre, I had access to a more controlled lighting environment and equipment, including a DSLR camera and colour checkers. The Digitization Manager, Laura Ramsey, and I utilized one lighting umbrella and a softbox, on either side of the room in two different set ups - one for the three smaller albums and another for the largest album.

For both set ups, the softbox was designated as the main light, put at a 45-degree angle to the object, and an umbrella was used as a fill light, arranged at a similar 45degree angle. The main goal was to position the pair of lights to evenly illuminate the surface and fill any extraneous shadows as a standard 'copy lighting' set up. We used an incident light meter and adjusted the lights to accommodate for the lift and silver mirroring on the prints of each page. I photographed with the camera tethered to a nearby computer, in order to check the focus of images more easily. 


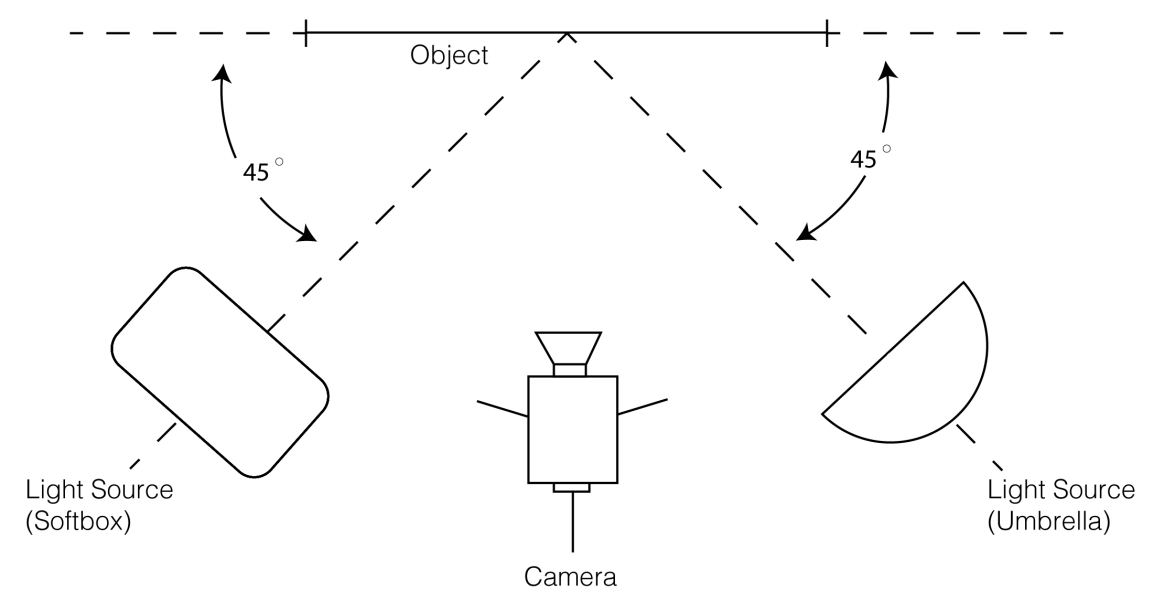

Figure 14. Lighting set-up for photo-documentation.

I photographed each album on top of a white board in order to create an overall, matched aesthetic. The smaller albums sat on the bed of the copy stand, laying flat on their own (as a result of extensive handling). When photographing the beginning and end of the smaller albums, small weights were used as props. The largest album was too big for the copy stand base and needed to be photographed on the floor. We experimented with an archival book pillow to help support the album further but ultimately, had the album laying flat on its own with foam pieces for supports when photographing the beginning and end of the album.

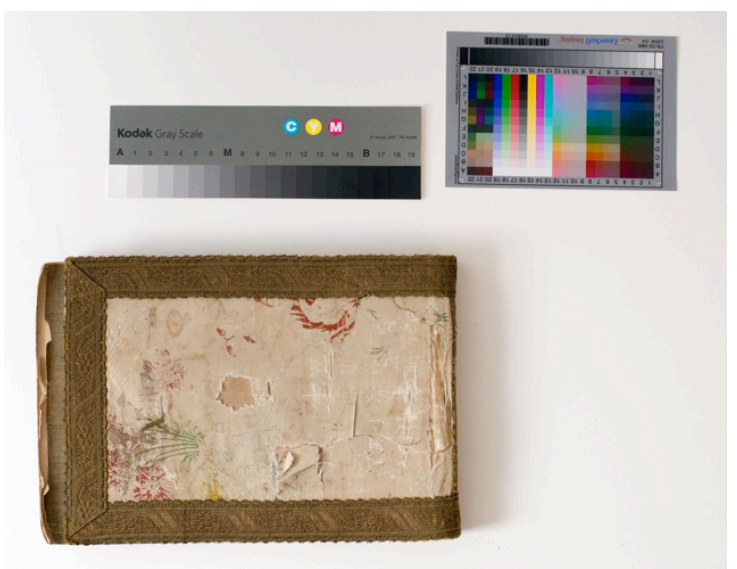

Figure 15. Photographic album with a colour checker and gray scale card. 
It was important to place the gray card and colour checker in the image at all times. These cards allow for a more accurate colour representation in post-production. However, the greatest challenge in photographing the albums was achieving even lighting across the surface of the page, without any glare or excessive reflection from the silver mirroring ${ }^{26}$ of the prints. I tried to reduce the glare by overlaying the album with a sheet of plexiglass but unfortunately, the sheet was too small to fully cover the album and would require extensive post-production treatment. Lighting was an ongoing concern throughout the photographing session and page turning became an acrobatic feat as Laura and I attempted to minimize any glare and reflection. There were several instances when a white card was used to bounce light. Other difficulties included the small size of the room, which limited the working area and lighting setup. As well, the camera shook from its weight on the Gobo arm, resulting in many unclear, out of focus images.

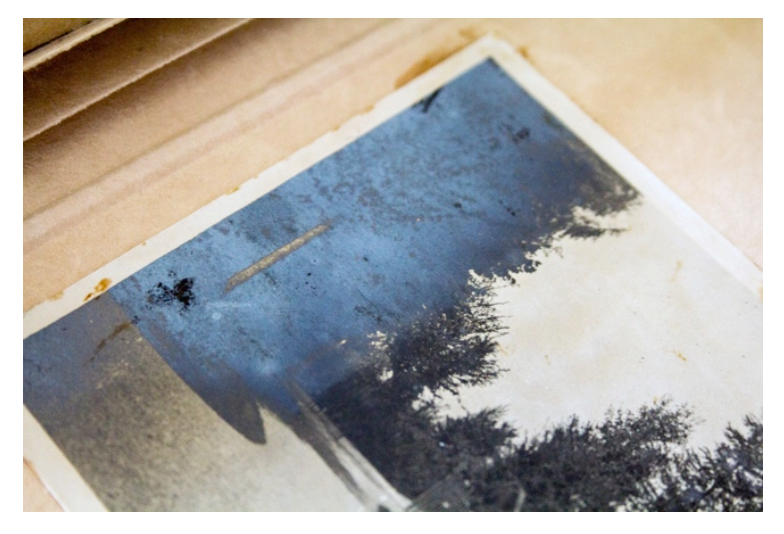

Figure 16. Silver mirroring, detail.

Unfortunately, when photographing private collections, one will likely be challenged by a lack of equipment and/or limited physical workspace. Ideally, depending on the project and cost, I might advise outsourcing this task to a freelance photographer who has access to an equipped studio. This option might be more cost efficient for some, considering the need of lighting and camera equipment. One would have to assess the

\footnotetext{
${ }^{26}$ This is a form of deterioration of photographic materials containing silver, often appearing as a bluishmetallic sheen. (See Figure 18.)
} 
collection in terms of the number of objects and their actual sizes but it is important to consider that the time saved can also allow the collection's owner to focus on other tasks. Furthermore, by hiring a professional photographer/digitization specialist, one is guaranteed a consistently high quality image output.

\section{g. Digitization: Post-Production}

As discussed in the production section, there are essentially three different modes for digitization, resulting in different postproduction techniques with each producing a master file with two working copies. The glass plates in good condition were scanned with a flatbed scanner at actual size as $\mathrm{dng}^{27}, 800 \mathrm{dpi}$, 64-bit RGBI color files. The files were then inverted into positives in Photoshop, converted to black and white and the image was flipped horizontally in order to achieve the correct image orientation. While this was done through a batch 'action,' some files were individually adjusted to pull back highlights or bring out shadows in order to obtain the most information. The glass plates that were in poor condition were documented with a DSLR camera. Similarly to the dng files produced with a scanner, the CR2 (raw) files produced with a camera capture highresolution color images of the plates. Since I photographed the plates with the emulsion facing upward, I did not need to flip the image orientation. The images only needed minor adjustments such as cropping, inversion and conversion to black and white.

\footnotetext{
${ }^{27}$ Digital Negative (DNG) is similar to a RAW image file but is a highly compatible and lossless image format, patented by Adobe.
} 

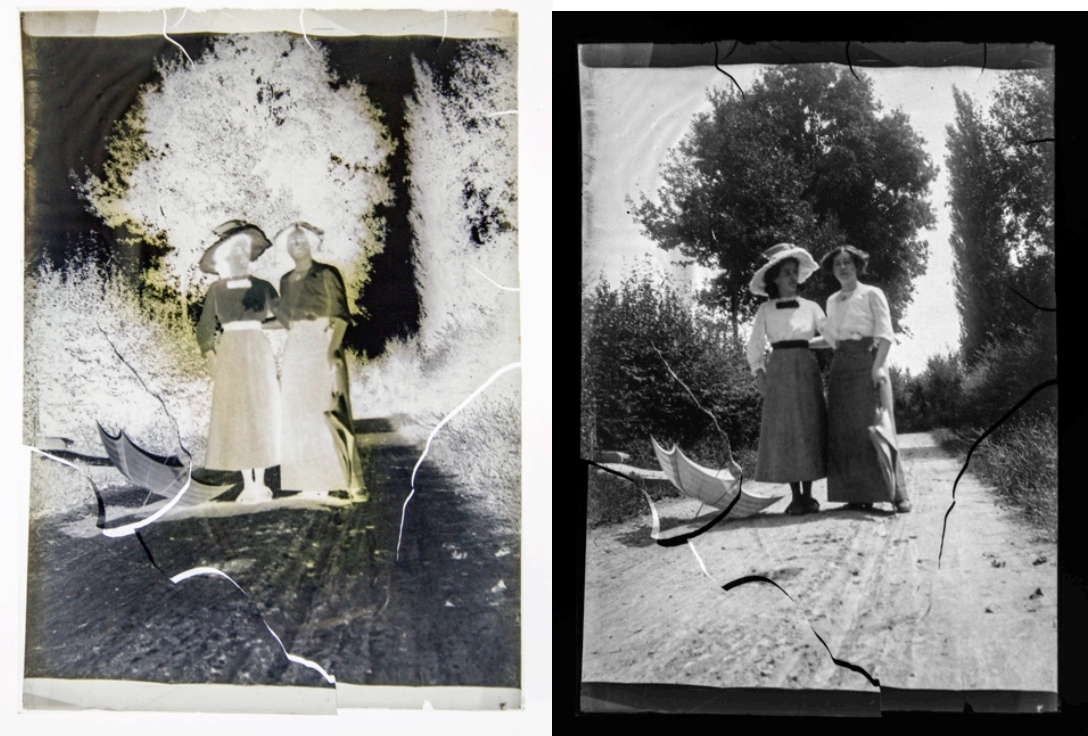

(Left) Figure 17. View of the glass plate negative, documented with DSLR.

(Right) Figure 18. View of the glass plate negative, inverted.

The albums were also documented with a DSLR camera, resulting in CR2 files. As these images were captured in the studio, we had more control over lighting and had access to a color checker. As a result, in post-production, I color balanced all the images and adjusted the levels accordingly. However, because the albums are 3D objects, they needed more aesthetic editing beyond simply cropping, including minimizing the shadows.

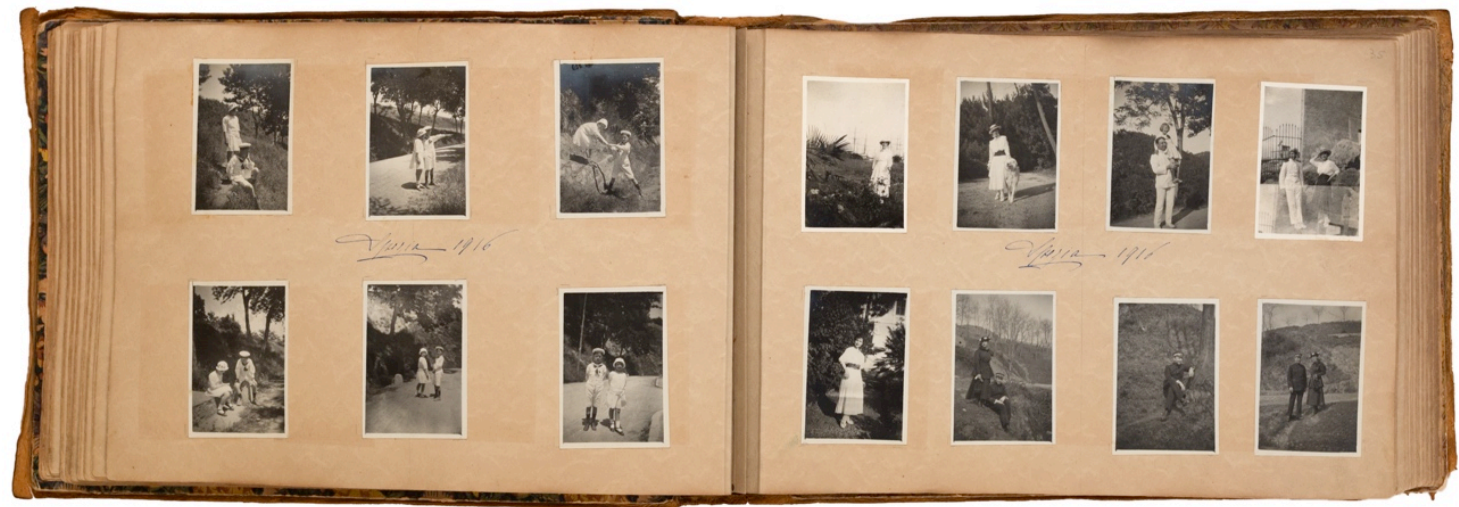

Figure 19. View of photographic album spread, digitally retouched. 
It is important to note the overall subjective nature of the post-production process. There are many different editing techniques that can be employed to varying degrees. While the original, master file should always serve as a direct, preservation copy of the object, the duplicate files have more leeway for adjustment, depending on the purpose of the image.

In fact, through the process of digitizing these objects, the statement that "everything unique is at risk" became very clear. ${ }^{28}$ While a digital file can be a representation of the object, it also has the potential to serve more purposes. After speaking with Betsy Eldridge, I realized the benefits of creating maquettes - physical copies duplicated from the digital files - not to replace the object itself but to help preserve the original object through minimizing its handling.

As a result, I realized that the organization and care of the digital files is as important as that of the physical objects. It was important to educate the collection's owner about this, including information on the various file types and folder structures that would be implemented in her digital collection. The digital files were organized under the folder that correlates with the series name. I decided to divide the files by type, i.e. one folder for the raw files (dngs and CR2s), another for the tiffs, and another for jpegs. These files, along with the database, are saved in multiple locations, including a laptop hard drive, two external hard drives, and cloud space via an automated backup system which was custom designed for the client/collection.

\section{h. The Digital Database}

In order to connect all the elements of this thesis project, I wanted to create a database that would help digitally organize Pope's collection and the related information she has gathered. I created a finding aid with one main fonds, the Pope Collection, and multiple series that list the object location, content, date range, creator, and amount of materials. I included a biographical sketch of the persons involved in the collection,

\footnotetext{
${ }^{28}$ Betsy Eldridge, conversation with author, 30 March 2016.
} 
including a family tree to provide context. Through this finding aid, I was able to create an overview of the collection as a starting point that could serve as an example for the collection's owner.

My initial thought was to create a cloud-based system to help organize the collection digitally but after further research and analysis, I opted to use a local, central database on her laptop hard drive. This gives the client has full control over the system and information, allowing for easier maintenance and updates of the local database. It also provides privacy reassurance for the client, avoiding the possibility of any security loopholes for on-line attacks or SQL injections (viruses) that could undermine the database.

I decided upon a database system (File Maker Pro), widely used across institutions, that is both affordable (one-time cost) and customizable. The database I created contains fields with some correspondence to those used in institutional archives and museums. However, I also consulted the collection's owner to learn which fields were important to her. While I wanted to create a system that closely resembles industry standards, I continually reminded myself that this is a private family collection.

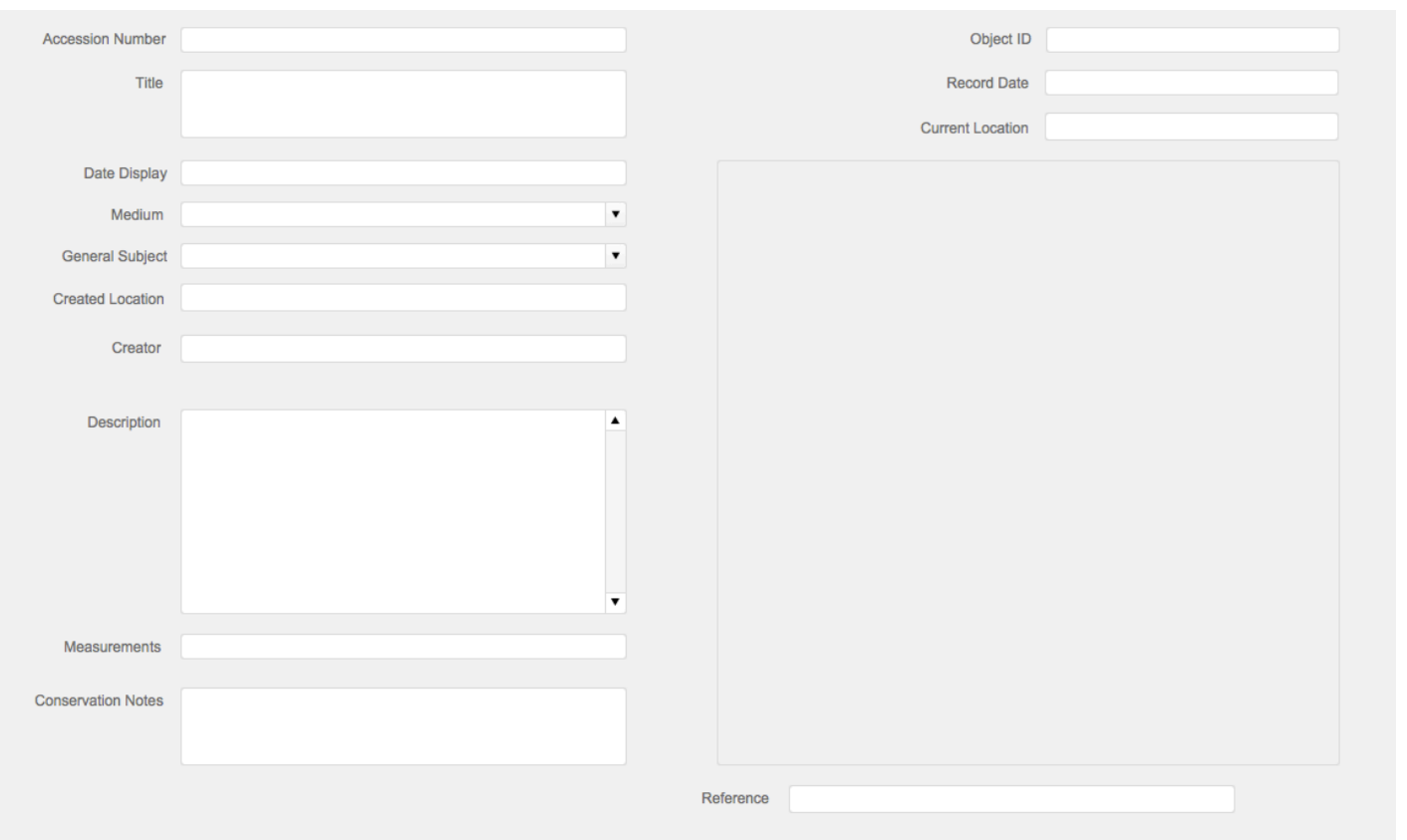

Figure 20. Sample record in File Maker Pro. 
Table 2. Database workflow.

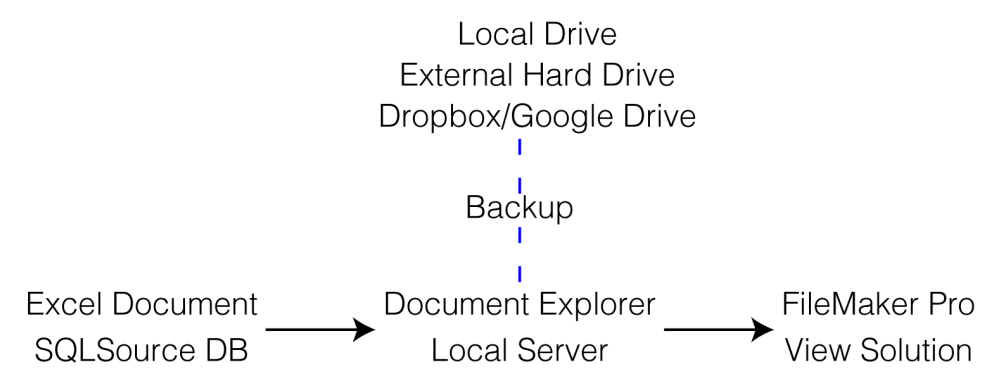

The many version of the database were organized with the following suggestion from David Kalman, a software engineer and CEO of Agura Labs: each version has one decimal point - the first number is the main version while the second number is the minor edits made within that version. For example, minor edits $1.1 \rightarrow 1.2$ while major edits would go from $1.2 \rightarrow 2.0$. Furthermore, as the many versions can be confusing, I have kept a document file, listing what changes were made in each version.

Kalman also provided me with a script that I used to program uploads to the database via a simple, user-friendly Microsoft Excel spreadsheet. Through this working method, everything is edited directly in the Excel spreadsheet in order to be uploaded directly into the database.

Table 3. Auto Transfer Code Snipit.

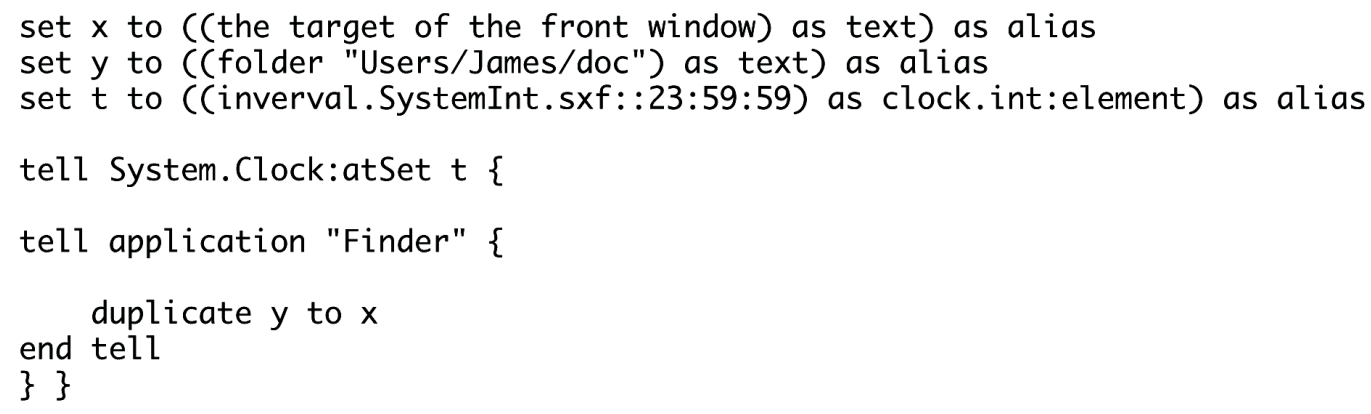

While the database and its fields can always be modified at a later date, I have created a combination of free text, automated fixed text, linked, and image fields within the database as follows: 
'Accession Number' is an automated, fixed text field that will include an abbreviation of the 'Fonds' followed by the 'Series' name, along with an object number. The object number was created at the beginning of the organization of the collection. It is as close to chronological order as we could initially date the plates. The numerous plates whose dates were initially unknown and later discovered, kept their object numbers but were physically placed in the 'correct' chronological order in the box.

Table 4. Breakdown of accession number.
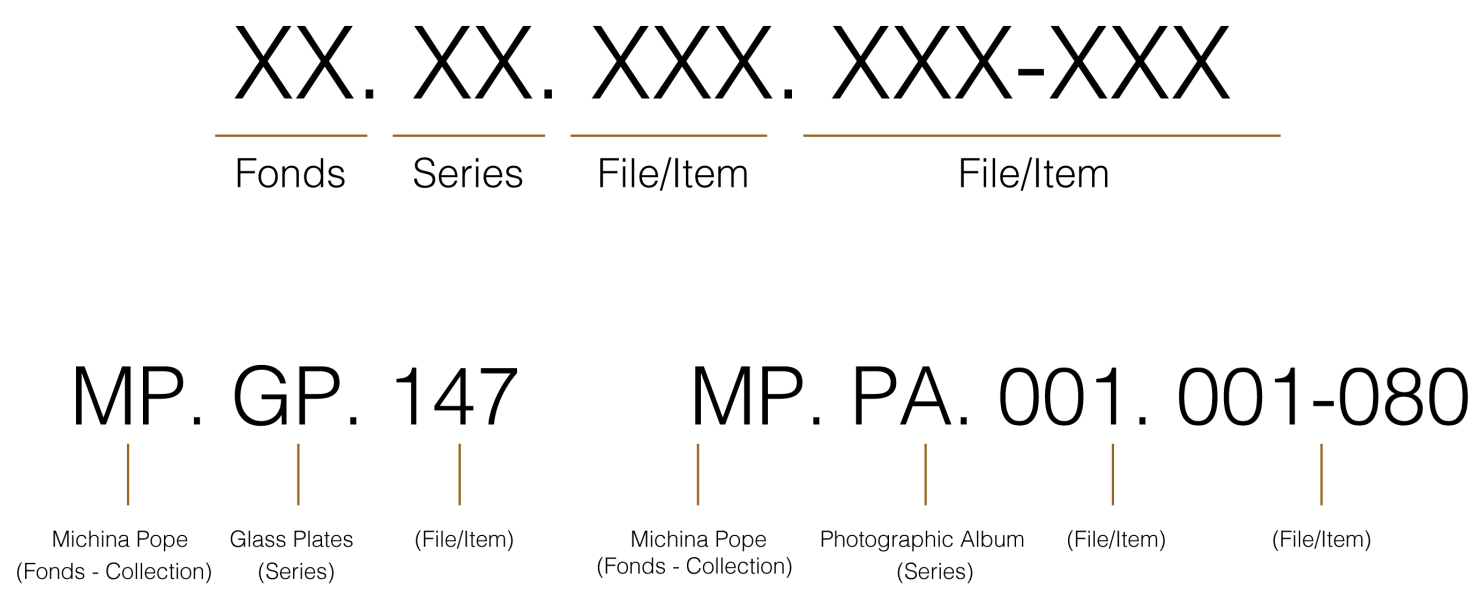

'Title' is a free text field that is to be used to create a short description of what the object/image is. It is to be used as an initial identifier. I did not feel the need to create a contextual field such as 'title type' as it is not an artist's collection etc. and all titles are descriptive. Any inscriptions from the albums or prints will be put in the description field. (See below for more information).

'Medium' identifies the type of object. After surveying Pope's collection and creating a finding aid, I created a reference list that includes all object types in her collection. If she finds other objects that do not fit any of the descriptions, it can be modified, similar to most of the fields.

The 'General Subject' is similar to the 'Medium' field and is to be used as a quick identifying field, allowing one to search by image subject, i.e. portrait, landscape, etc. 
The 'Place of Creation' is simply the location that the object was created and the 'Creator' identifies who created the object, if known. Both these fields are free text fields but must always be filled. In fact, if any field is ever unknown, it will be labeled as such, instead of just being left blank.

The 'Description' is a free text field, allowing the collection's owner to add any new information she discovers about the images or people depicted in them, etc.

'Measurements' is another free text field that lists the dimensions of the object, in centimetres to the second decimal place.

'Conservation Notes' is free text field that allows for any notes on the state and deterioration of the object. This field is mainly for the consultant and any other professional that comes to survey the collection.

'Image/Documentation' is a field that holds the photo documentation of the object. 'Reference' is a field that allows records to be linked. For example, if a print made from one of the glass plate negatives can be seen on a specific photographic album page, the album record is listed on the glass plate negative record. Up to four records can currently be linked, corresponding to the four photographic albums. However, this can also be altered at a later date if more correlations are discovered between objects, i.e. letters.

The two more technical fields of the database include 'Record Date', a fixed field that is automatically filled out when the record is created, and 'Current Location,' a free text field that allows one to locate the object in the collection, anywhere from the room to the exact box. 
Table 5. Technical database fields.

\begin{tabular}{|c|c|c|}
\hline Field_ID & Field_Name & Field_Type \\
\hline 1 & Accession Number & Automated, fixed text field \\
\hline 2 & Title & Free text field \\
\hline 3 & Medium & Drop-down field \\
\hline 4 & General Subject & Drop-down field \\
\hline 5 & Place of Creation & Free text field \\
\hline 6 & Creator & Free text field \\
\hline 7 & Description & Free text field \\
\hline 8 & Measurements & Free text field \\
\hline 9 & Conservation Notes & Image field \\
\hline 10 & Image/Documentation & Link field \\
\hline 11 & Reference & Automated, fixed text field \\
\hline 12 & Object ID & Automated, fixed text field \\
\hline 13 & Record Date & Free text field \\
\hline 14 & Current Location & \\
\hline & & \\
\hline
\end{tabular}

I have created a logistical manual for the collection's owner so that she is able to further input data, adding any additional information or works relevant to the collection. This manual defers to common standards for cataloguing. For example, many of Pope's original names and places etc. were listed in Italian and we decided to use the English equivalents for the sake of standardization, acknowledging that any Italian references can be put in the description field. The manual also includes guidelines for the Excel spreadsheet, along with any possible 'troubleshooting' with the actual functionality of the Filemaker Pro database. Throughout the preservation process, it was important for me, as a consultant, to reassure the collection's owner that she is well equipped to care for the collection after my current role is finished. I found that written instructions and manuals 
helped with this, allowing, for example, references to be made to instructions regarding physical housing, environment, and database entry, etc.

\section{CONCLUSION}

A primary goal for this project was to attempt to apply known institutional preservation practices to a privately owned collection of family photographs. It became apparent early on that a private collection is inherently different from a collection held by a public institution. An institution with a regulated environment provides trained personnel who are knowledgeable about safe handling protocols. In contrast, a private collection often exists in someone's home or a storage unit, where both space and environmental controls are compromised, and the "staff" consists only of the (usually amateur) collector and his/her consultant. The limited human resources influence the sequence of events and may extend the timeline of the project. Although challenging, there are ways to physically adapt a space, educate the collection's owner on proper practices, and create a viable workflow regarding the preservation of his/her collection.

The initial challenge was one of alignment between the owner and the consultant. In order to record and manage expectations, I recommend creating a document to be signed by both parties. This document will protect the privacy of the owner and his/her collection while defining the rights and responsibilities of the consultant. Through this, a professional working relationship can be established. Although I did not do this at the initiation of the project, I am grateful that it did not have a detrimental effect on my working relationship with the owner. A level of trust between the consultant and the owner is vital in order for the consultant to fully access the materials in the collection.

Access to the collection exists on both an intellectual and physical level. Intellectual access provides the consultant with the information needed to evaluate the materials' 'worth' beyond their materiality. When the consultant understands the importance of the images as well as the objects, he/she can develop a partnership with the owner, laying the groundwork for a quality, interactive relationship. At the same time, 
physical access entails the ability to both see and handle the objects with minimal limitations. Unfortunately, unlike an institution with predetermined hours and tasks, working with a private collector can mean that materials are not always accessible and the collector guides both one's timeline and priorities.

A mutual understanding between the owner and the consultant from the beginning is vital to the success of the project. The consultant must offer the owner viable options for consideration, specific to their collection, including full explanations of the efficacy and potential costs. Pope was understanding and flexible in allocating funds, as they became needed throughout the process. In hindsight, however, a preferred approach is to prepare an estimate of probable costs for the entire project.

As the sole consultant, I became aware of the subjective nature of my decisions. My advice not only affects the material preservation but can also affect the outcome of the appearance of the images. I included the collection's owner at each stage of the preservation process for input on decisions. While this provided a strong foundation for collaboration, it sometimes slowed down the process. However, I consider this a small sacrifice.

An educational component is integral to the process. The consultant must prepare the owner of the collection to be the future collections manager. As a consultant, I have the current responsibility to provide the owner with the tools necessary to independently maintain the preservation of her collection. I recommend the creation of a series of manuals, tailored for the collection's owner. Each manual should consist of illustrated instructions, beginning with the basic settings on the scanner to more complicated database input. I recommend periodic consultation with a consultant for 'maintenance checks' on a collection. However, it is the owner's responsibility to pass on the knowledge and processes, learned through the consultant, to the next potential owner, if possible.

I realize that this project is not an isolated case. This is just one example of a broader group of private collectors with a desire to preserve a piece of their family history. Many may be at the age of retirement, having grown up with widespread access 
to personal use, amateur cameras that were used to capture unscripted, everyday life and events. The resulting physical images manifested themselves in multiple copies of prints and albums, representing some of the last physically born photographic objects before the digital era. This is both a historical and educational opportunity to encourage more people to preserve their family's artifacts.

Although my thesis only highlights one family's collection, I discovered the incredible value of working with a private collector. Every collection has potential significance to the owner and their family, social history, and photographic history. It is important for me to remember the emotional connection of the owner to his/her family's collection. Furthermore, my own personal fulfillment of ensuring the survival of historical artifacts is immeasurable. 


\section{BIBLIOGRAPHY}

Albright, Gary. "Photograph Albums. Some Thoughts on Treatment." In Postprints of the Photographic Materials Group Winter Meeting. February 1 and 21985.

Philadelphia. AIC, 1985.

Balloffet, Nelly. Preservation and Conservation for Libraries and Archives. Chicago: American Library Association, 2005.

Beaudoin, Joan E. "Context and Its Role in the Digital Preservation of Cultural Objects." D-Lib Magazine, Vol. 18, no. 11/12 (November/December 2012). Accessed 24 September 2015.

http://www.dlib.org/dlib/november12/beaudoin/11beaudoin1.html.

Botelho, Alexandra. "A Report on the Photo Album Condition Assessment Survey for the International Museum of Photography and Film at George Eastman House." Rochester: George Eastman House, 1997.

Bray, Charles. Dictionary of Glass: Materials and Techniques. London: A \& C Black Limited, 2001.

Brown, Barbara. "Photographs in Albums: Observations, Treatments Comments, and Some Survey Results." In Conservation of Scrapbooks and Albums. Postprints of the Book and Paper Group and Photographic Materials Group Joint Session at the 27th Annual Meeting of the American Institute for Conservation of Historic and Artistic Works. June 11, 1999. St. Louis, Missouri, 69-79. Washington: AIC, 2000.

Brown, Meg. "Developing a Conservation Survey Database for Photograph Albums." In Conservation of Scrapbooks and Albums. Postprints of the Book and Paper Group and Photographic Materials Group Joint Session at the 27th Annual Meeting of the American Institute for Conservation of Historic and Artistic Works. June 11, 1999. St. Louis, Missouri, 69-79. Washington: AIC, 2000.

Brown, Meg. "Glossary of Terms for the Photograph Album Survey." In Conservation of Scrapbooks and Albums. Postprints of the Book and Paper Group and Photographic Materials Group Joint Session at the 27th Annual Meeting of the American Institute for Conservation of Historic and Artistic Works. June 11, 1999. St. Louis, Missouri, 85-92. Washington: AIC, 2000.

Cataloging Cultural Objects: A Guide to Describing Cultural Works and Their Images. Chicago: American Library Association, 2006. Accessed 24 September 2015. http://personal.sirma.bg/vladimir/cco/Cataloging_Cultural_Objects.pdf. 
Clarke, Bryan. "Some Observations on the Development of Albums Containing Photographs and Aspects of their Deterioration." In The Imperfect Image: Photographs their Past Present and Future, 69-77. Windermere: Centre for Photographic Conservation, 1992.

Conway, Paul. "Modes of Seeing: Digitized Photographic Archives and the User Experienced User." The American Archivist, Vol. 73 (Fall / Winter 2010): 425 462.

Conway, Paul, and Ricardo Punzalan. "Fields of Vision: Toward a New Theory of Visual Literacy for Digitized Archival Photographs." Archivaria 71 (Spring 2011): 63-97.

Craven, Louise, ed. What Are Archives? Cultural and Theoretical Perspectives: A Reader. Burlington: Ashgate, 2008.

DeCandido, Robert. Collections Conservation. Washington, D.C.: Association of Research Libraries, 1993.

Dlugosz, Olga M. "Digital Application Solutions in Collection Management: The Photographer's Catalogue, A Case Study, Sally Mann.” Master's thesis, Ryerson University, 2007.

Federal Agencies Digitization Initiative - Still Image Working Group. Technical Guidelines for Digitizing Cultural Heritage Materials: Creation of Raster Image Master Files. Washington, D.C., 2010. http://www.digitizationguidelines.gov/guidelines/FADGI_Still_ImageTech_Guidelines_2010-08-24.pdf.

Flieder, Françoise; Garnier, Chantal; Gillet, Martine. "Glass Plate Negatives: Preservation and Restoration" Restaurator 7, no. 2 (1989): 49-80.

Gladney, Henry M. "Long-Term Preservation of Digital Records: Trustworthy Digital Objects." The American Archivist, Vol. 72 (Fall/Winter 2009): 401-435.

Hamburg, Doris. "Storage Alternatives for Photographic Albums." In Postprints of the Photographic Materials Group Winter Meeting. February 1 and 21985. Philadelphia. AIC, 1985.

Hendricks, Klaus. "Care of Black-and-White Photographic Glass Plate Negatives." CCI Notes 16.2. Ottowa: Canadian Conservation Institute, 2007. Accessed 31 May 2015. http://canada.pch.gc.ca/eng/1439925171071. 
Hendriks, Klaus. "Conservation of Albums, Scrapbooks and Portfolios.” In Fundamentals of Photograph Conservation: A Study Guide, 325-330. Toronto: Lugus, 1991.

Hill, Gregory. "The Conservation of a Photograph Album at the National Archives of Canada." Journal of the American Institute for Conservation, Vol. 30, no. 1 (1991): 75-88.

Horton, Richard W. "Glossary of Terms Relating to Photo Albums." In Conservation of Scrapbooks and Albums. Postprints of the Book and Paper Group and Photographic Materials Group Joint Session at the 27th Annual Meeting of the American Institute for Conservation of Historic and Artistic Works, 3-12. Washington, D.C.: AIC, 2000.

Hunter, Gregory S. Maintaining Practical Archives: A How-to-do-it Manual. 2nd ed. New York: Neal- Schuman Publishers, Inc., 2003.

Knapper, Ross. "In Fragile State: The Conservation Authorities Branch Photographs Albums at the Archives of Ontario.” Masters thesis, Ryerson University, 2013.

Larew, Elizabeth. "Not Just the Paris Portraits: Preserving Berenice Abbott's Glass Plate Negatives.” Master's thesis, Ryerson University, 2015.

Lavédrine, Bertrand. A Guide to the Preventive Conservation of Photograph Collections. Los Angeles: Getty Publications, 2003.

Library of Congress. "Prokudin-Gorskii Collection: Digitizing the Collection - Prints \& Photographs Online Catalogue.” Accessed 07 October 2015. http://www.loc.gov/pictures/collection/prok/digitizing.html.

Lozano, Gustavo. "History and Conservation of Albums and Photographically Illustrated Books." Advanced Residency Program in Photograph Conservation, George Eastman House, 2007.

McCabe, Constance, ed. Coatings on Photographs: Materials, Techniques, and Conservation. Washington, D.C.: American Institute for Conservation, 2005.

O'Brien, Jeff. BASIC RAD: An Introduction to the Preparation of Fonds-and Series-level Descriptions Using the Rules for Archival Description. Regina: The Saskatchewan Council of Archives, 1997. Accessed 07 October 2015. http://scaa.sk.ca/rad/rad4.pdf. 
Ogden, Sherelyn. "Preservation Options for Scrapbook and Album Formats," in The Book and Paper Group Annual, Vol. 10 (1991). Accessed 24 September 2015. http://cool.conservation-us.org/coolaic/sg/bpg/annual/v10/bp10-14.html.

“Online Gallery Turning The Pages.” British Library Online. Accessed 12 October 2015. www.bl.uk/onlinegallery/ttp/ttpbooks.html.

Osterman, Mark. "Introduction to Photographic Equipment, Processes, and Definitions of the 19th Century," in The Focal Encyclopedia of Photography, ed. Michael R. Peres, 36-123. New York: Focal Press, 2007.

Perry, Shannon Leigh. ““'So you want a Database” A Beginner's Guide to Database Technology for Small Cultural Institutions." Master's thesis, Ryerson University, 2006.

"Preservation Self-Assessment Program (PSAP) | Negatives." University of Illinois at Urbana-Champaign Institute of Museum and Library Services. Accessed 09 October 2015. https://psap.library.illinois.edu/format-id-guide/negative.

Preserving Your Family Photographs. Cornell University Library Department of Preservation and Conservation, 2001. Accessed 31 May 2016. https://www.library.cornell.edu/preservation/brochure/Family\%20Photos\%20Text $\% 2001 . p d f$

Primanis, Olivia. "Nineteenth-Century Photograph Albums: Structure, Condition, and Treatments." In Conservation of Scrapbooks and Albums. Postprints of the Book and Paper Group and Photographic Materials Group Joint Session at the 27th Annual Meeting of the American Institute for Conservation of Historic and Artistic Works. June 11, 1999. St. Louis, Missouri, 47-64. Washington: AIC, 2000.

Psaila, Denise. "Design and Materials for Photographic Housing." Master's thesis, Ryerson University, 2006.

Rekrut, Ala. "Material Literacy: Reading Records as Material Culture." Archivaria 60 (Fall 2005): 11-38.

Ritzenthaler, Mary Lynn and Vogt-O'Connor, Diane, et al. Photographs: Archival Care and Management. Chicago: Society of American Archivists, 2006.

Roosa, Mark. Care, Handling, and Storage of Photographs. Paris: IFLA-PAC, 2004. 
Rules for Archival Description. Ottawa: Canadian Council of Archives, 2008. Accessed 07 October 2015. http://www.cdncouncilarchives.ca/RAD/RADComplete_July2008.pdf

Sassoon, Joanna. "Photographic Materiality in the Age of Digital Reproduction." In Photographs Objects Histories: On the Materiality of Images, ed. Elizabeth Edwards and Janice Heart, 186-202. New York: Routledge, 2004.

Schwartz Joan M. "Negotiating the Visual Turn: New Perspectives on Images and Archives." The American Archivist, Vol. 67 (Spring/Summer 2004): 107-122.

Teper, Jennifer Hain. "An Introduction to Preservation Challenges and Potential Solutions for Scrapbooks in Archival Collections." Journal of Archival Organization, Vol. 5, Issue 3 (2007): 47-64.

"The Photo Album as Cultural Artifact." In L'Album Photographique. Histoire et Conservation d'un Object, 39-48. Paris: Section Française de l'Institut International de Conservation, 1998.

Valverde, María Fernanda. "Photographic Negatives: Nature and Evolution of Processes." Advanced Residency Program, George Eastman House, 2005.

Wagner, Sarah S., and Miranda Martin. "How Do I House Glass Plate Negatives?" The U.S. National Archives and Records Administration, 18 June 2001. Accessed 07 October 2015. http://www.archives.gov/preservation/storage/glass_plate_negatives.html.

Whitman, Katharine. "The History and Conservation of Glass Supported Photographs.” Advanced Residency Program, George Eastman House, 2007.

Willumson, Glenn. "The Getty Research Institute: Materials for a New Photo-History." History of Photography 22, no. 1 (Spring 1998): 31-39.

Zucker, Barbara. "Preservation of Scrapbooks and Albums." Preservation Basics: A National Cooperative Information Project, Leaflet no. 1. Washington, D.C.: Library of Congress, 1991. Accessed 07 October 2015. http://www.loc.gov/preservation/care/scrapbk.html. 